\title{
Radiative forcing and climate response to projected 21st century aerosol decreases
}

\author{
D. M. Westervelt ${ }^{1}$, L. W. Horowitz ${ }^{2}$, V. Naik ${ }^{3}$, J.-C. Golaz ${ }^{2}$, and D. L. Mauzerall ${ }^{1,4}$ \\ ${ }^{1}$ Program in Science, Technology, and Environmental Policy, Woodrow Wilson School of Public and \\ International Affairs, Princeton University, Princeton, NJ, USA \\ ${ }^{2}$ Geophysical Fluid Dynamics Laboratory, National Oceanic and Atmospheric Administration, Princeton, NJ, USA \\ ${ }^{3}$ UCAR/NOAA Geophysical Fluid Dynamics Laboratory, Princeton, NJ, USA \\ ${ }^{4}$ Department of Civil and Environmental Engineering, Princeton University, Princeton, NJ, USA
}

Correspondence to: D. L. Mauzerall (mauzeral@ princeton.edu)

and D. M. Westervelt (danielmw@ princeton.edu)

Received: 25 February 2015 - Published in Atmos. Chem. Phys. Discuss.: 27 March 2015

Revised: 4 November 2015 - Accepted: 6 November 2015 - Published: 16 November 2015

\begin{abstract}
It is widely expected that global emissions of atmospheric aerosols and their precursors will decrease strongly throughout the remainder of the 21 st century, due to emission reduction policies enacted to protect human health. For instance, global emissions of aerosols and their precursors are projected to decrease by as much as $80 \%$ by the year 2100, according to the four Representative Concentration Pathway (RCP) scenarios. The removal of aerosols will cause unintended climate consequences, including an unmasking of global warming from long-lived greenhouse gases. We use the Geophysical Fluid Dynamics Laboratory Coupled Climate Model version 3 (GFDL CM3) to simulate future climate over the 21st century with and without the aerosol emission changes projected by each of the RCPs in order to isolate the radiative forcing and climate response resulting from the aerosol reductions. We find that the projected global radiative forcing and climate response due to aerosol decreases do not vary significantly across the four RCPs by 2100 , although there is some mid-century variation, especially in cloud droplet effective radius, that closely follows the RCP emissions and energy consumption projections. Up to $1 \mathrm{~W} \mathrm{~m}^{-2}$ of radiative forcing may be unmasked globally from 2005 to 2100 due to reductions in aerosol and precursor emissions, leading to average global temperature increases up to $1 \mathrm{~K}$ and global precipitation rate increases up to $0.09 \mathrm{~mm} \mathrm{day}^{-1}$. However, when using a version of $\mathrm{CM} 3$ with reduced present-day aerosol radiative forcing $\left(-1.0 \mathrm{~W} \mathrm{~m}^{-2}\right)$, the global temperature increase for
\end{abstract}

RCP8.5 is about $0.5 \mathrm{~K}$, with similar magnitude decreases in other climate response parameters as well. Regionally and locally, climate impacts can be much larger than the global mean, with a $2.1 \mathrm{~K}$ warming projected over China, Japan, and Korea due to the reduced aerosol emissions in RCP8.5, as well as nearly a $0.2 \mathrm{~mm} \mathrm{day}^{-1}$ precipitation increase, a $7 \mathrm{~g} \mathrm{~m}^{-2}$ LWP decrease, and a $2 \mu \mathrm{m}$ increase in cloud droplet effective radius. Future aerosol decreases could be responsible for $30-40 \%$ of total climate warming (or 10-20\% with weaker aerosol forcing) by 2100 in East Asia, even under the high greenhouse gas emissions scenario (RCP8.5). The expected unmasking of global warming caused by aerosol reductions will require more aggressive greenhouse gas mitigation policies than anticipated in order to meet desired climate targets.

\section{Introduction}

The climate effects of atmospheric aerosols represent one of the most uncertain aspects of current and future climate forcing and response estimates (Myhre et al., 2013). Whereas the greenhouse gas warming influences on climate are relatively well understood, significant questions remain regarding the magnitude, and in some cases, even the sign (cooling or warming), of aerosol-climate interactions. Aerosol radiative forcing of climate can be split into two categories: the direct effect, in which atmospheric aerosols directly scatter 
or absorb incoming solar radiation; and the indirect effect, in which aerosols modify cloud properties which in turn affect the radiation budget. For a fixed amount of cloud water, a more polluted air mass will have smaller and more numerous cloud droplets, leading to a larger surface area and a brighter cloud (Twomey, 1974). This is known as the cloud albedo effect. In addition, more aerosol pollution may also result in a longer cloud lifetime due to the tendency of smaller droplets to remain suspended in the atmosphere longer (Albrecht, 1989), although this cloud lifetime effect is not as well understood. On a global average basis, both the direct and indirect effects tend to exert a net negative radiative forcing on present-day climate, opposing the positive forcing from greenhouse gases, with the total aerosol effective radiative forcing estimated to be $-0.9 \mathrm{~W} \mathrm{~m}^{-2}$ (uncertainty range -1.9 to $-0.1 \mathrm{~W} \mathrm{~m}^{-2}$ ) (Myhre et al., 2013). This aerosol forcing has likely offset a significant portion of present-day $\mathrm{CO}_{2}$ and other greenhouse gas-induced climate forcing and subsequent global warming. Likewise, any changes in future anthropogenic aerosols will have implications for the overall net impact on climate. Here we evaluate the changes in global and regional aerosol burden, climate forcing, and climate response due to future decreases in aerosol and precursor emissions as projected by all of the Representative Concentration Pathways (RCPs). We build upon the work of Levy et al. (2013) to contrast the global and regional climate response and quantify the expected unmasking of warming due to future aerosol reductions across all of the RCPs.

Emissions of aerosols and their precursors have increased dramatically since the preindustrial era, due to increasing industrialization and global population. In 2012, air pollution, mostly in the form of atmospheric aerosols, was responsible for 7 million deaths (3.7 million from ambient air pollution, 3.3 million from indoor) worldwide (WHO, 2014). Due to efforts to reduce this enormous human health impact, aerosol and precursor emissions are expected to decline worldwide over the next several decades as governments enact and enforce stricter emission control policies. Emissions of sulfur dioxide $\left(\mathrm{SO}_{2}\right.$, a precursor to sulfate aerosol) have already declined about $50 \%$ in North America and western Europe and passed their peak in 2005 in China (Klimont et al., 2013). In some developing countries, emissions are still rising but are expected to begin to decline within the next few decades, as a consequence of increasing affluence and more environmental regulation (van Vuuren et al., 2011a).

While clearly beneficial for human health, declining aerosol emissions will result in the unintended consequence of unmasking additional climate warming, due to the reduction of the cooling effects from anthropogenic aerosols such as sulfate and organic carbon (OC). Thus, careful policy implementation is necessary in order to maximize reduction of unhealthy air pollution while also minimizing the unmasking of additional global warming. Some studies have pointed to reductions in black carbon as a possible approach to address this dilemma (Bond et al., 2013; Kopp and Mauzerall,
2010; Shindell et al., 2012a). Black carbon (BC) is an aerosol species that is a strong absorber of incoming solar radiation in the troposphere and thus a climate-warming agent. It is also a major contributor to $\mathrm{PM}_{2.5}$ and has an adverse effect on human health (Bond et al., 2013). Despite a clear human health benefit, questions remain whether its reduction will be an effective strategy for avoiding additional warming, due to its frequent co-emission with two strong cooling species, OC and sulfate (Chen et al., 2010; Reddington et al., 2013). Some sources of BC are not large sources of species that exert a negative radiative forcing (e.g. diesel fuel combustion), so it has been suggested that these should be preferentially targeted for control first (Kopp and Mauzerall, 2010; Shindell et al., 2012a).

Modeling studies have suggested that aerosols also have strong impacts on precipitation, cloud cover, cloud droplet size and number, atmospheric circulation, and other climate parameters (Lohmann and Feichter, 2005; Ming and Ramaswamy, 2009, 2011; Ming et al., 2011; Ramanathan et al., 2001; Rosenfeld et al., 2008; Stevens and Feingold, 2009). An increase in aerosol emissions tends to decrease local to regional precipitation rates (warm rain), through macrophysical and microphysical processes: (1) less incoming solar radiation penetrates the troposphere and reaches the surface, resulting in less evaporation (Ramanathan et al., 2001) and (2) smaller and more abundant aerosols lead to smaller cloud droplets, which are less likely to convert to rain drops via coalescence on the local and regional scale (Radke et al., 1989; Rosenfeld, 2000). An exception to (1) is BC or other absorbing aerosols, which may have opposing effects on precipitation through heating the atmosphere (causing stabilization and reduction in precipitation) and warming the surface via redistributed thermal energy (causing an enhancement of precipitation) (Ming et al., 2010). However, the net effect of increasing aerosol concentrations tends to be suppression of precipitation. Thus, the expected reduction of aerosol concentrations should increase rainfall rates (warm rain) globally. Since aerosols serve as seeds for virtually all liquid cloud formation in the atmosphere, decreases in aerosols may also be expected to affect cloud cover, cloud liquid water path, and effective cloud droplet radius.

To estimate future aerosol emissions and burden, radiative forcing, and climate response, we must utilize future projections or scenarios. The current state-of-the-art emissions scenarios for global climate modeling are the Representative Concentration Pathways (RCPs) (Lamarque et al., 2011; Masui et al., 2011; Riahi et al., 2011; van Ruijven et al., 2008; Thomson et al., 2011; van Vuuren et al., 2012, 2011a, b). The RCPs are different from previously developed scenarios in that they are initialized with radiative forcing beginning and endpoints (2005-2100). A consistent but non-unique pathway based on literature and integrated assessment modeling is then selected to match the prescribed endpoint. There are four scenarios, each named for a radiative forcing endpoint in 2100 of 2.6, 4.5, 6.0, and $8.5 \mathrm{~W} \mathrm{~m}^{-2}$ 
Table 1. Summary of previous global climate modeling studies examining future climate effects of aerosols (only those using RCP projections).

\begin{tabular}{|c|c|c|c|c|c|c|}
\hline Work & Model & RCPs & Output & Domain & Aerosol & Results \\
\hline Levy et al. (2013) & GFDL CM3 & 4.5 & $\begin{array}{l}\text { Emis., AOD, } T, P \text {, } \\
\text { RF }\end{array}$ & Global, 1860-2100 & $\begin{array}{l}\text { Fixed } 2005 \\
\text { emissions }\end{array}$ & $\begin{array}{l}1.26 \mathrm{~W} \mathrm{~m}^{-2}, 1^{\circ} \mathrm{C} \text {, } \\
0.1 \mathrm{~mm} \mathrm{day}^{-1}\end{array}$ \\
\hline Shindell et al. (2013) & Multimodel & All & Emis, AOD, RF & Global, 1850-2100 & Fixed for RF calc. & $0.68-1.42 \mathrm{~W} \mathrm{~m}^{-2}$ \\
\hline Rotstayn et al. (2013) & CSIRO-Mk3.6 & 4.5 & $\begin{array}{l}\text { Emis, burden, } \\
\text { AOD, RF, } T, P\end{array}$ & Global, 1850-2100 & $\begin{array}{l}\text { Fixed } 2005 \\
\text { emissions }\end{array}$ & $\begin{array}{l}1.46 \mathrm{~W} \mathrm{~m}^{-2}, \\
1.1^{\circ} \mathrm{C}, \\
0.1 \mathrm{~mm} \mathrm{day}^{-1}\end{array}$ \\
\hline Gillett and von Salzen (2013) & CanESM2 & $\begin{array}{l}2.6,4.5 \\
8.5\end{array}$ & Emis, burden, $T$ & Global, 1850-2100 & $\begin{array}{l}\text { Fixed } 2000 \\
\text { emissions }\end{array}$ & $0.4-0.7^{\circ} \mathrm{C}$ \\
\hline Chalmers et al. (2012) & HadGEM2-ES & $2.6,4.5$ & $\begin{array}{l}\text { Burden, RF, AOD, } \\
\text { CDNC, CLD, SW }\end{array}$ & Global, 2000-2037 & $\begin{array}{l}\text { Compare RCP2.6 } \\
\text { and RCP4.5 }\end{array}$ & $\begin{array}{l}\text { See Chalmers et } \\
\text { al. (2012) }\end{array}$ \\
\hline Takemura (2012) & SPRINTARS & All & $\begin{array}{l}\text { Emis, burden, } \\
\text { AOD, RF, } R_{\text {eff }} \text {, } \\
\text { LWP, IWP }\end{array}$ & $\begin{array}{l}\text { Global, regional, } \\
1850-2100\end{array}$ & $\begin{array}{l}\text { Compare to } 2000 \\
\text { levels }\end{array}$ & $1.72-1.96 \mathrm{~W} \mathrm{~m}^{-2}$ \\
\hline Lamarque et al. (2011) & CAM5 & All & $\begin{array}{l}\text { Emis, burden, } \\
\mathrm{AOD}, \mathrm{RF}, \mathrm{O}_{3}\end{array}$ & $\begin{array}{l}\text { Global, regional, } \\
1850-2100\end{array}$ & $\begin{array}{l}\text { Compare to } 2000 \\
\text { levels }\end{array}$ & $0.44-0.57 \mathrm{~W} \mathrm{~m}^{-2}$ \\
\hline Bellouin et al. (2011) & HadGEM2-ES & All & $\begin{array}{l}\text { Emis, AOD, } \\
\text { RF }\end{array}$ & Global, 2000-2100 & $\begin{array}{l}\text { Compare to } 2000 \\
\text { levels }\end{array}$ & $\sim 1 \mathrm{~W} \mathrm{~m}^{-2}$ \\
\hline This work & GFDL CM3 & All & $\begin{array}{l}\text { Emis, AOD, RF, } T, \\
P, \text { Cld, } R_{\text {eff }}\end{array}$ & $\begin{array}{l}\text { Global, regional, } \\
1860-2100\end{array}$ & $\begin{array}{l}\text { Fixed } 2005 \\
\text { emissions }\end{array}$ & See Tables 3-5 \\
\hline
\end{tabular}

(RCP2.6, RCP4.5, RCP6, and RCP8.5). Each scenario contains emissions and/or concentrations for all major greenhouse gases and air pollutants, including emissions of three aerosol/precursor species: $\mathrm{SO}_{2}$, OC, and $\mathrm{BC}$. All RCPs assume an autonomous change in future air pollution control policies in every world region, resulting in sharp decreases in regional and global emissions of $\mathrm{SO}_{2}, \mathrm{OC}$, and $\mathrm{BC}$.

There have been several previous studies on the effects of diminishing emissions of aerosols and their precursors on aerosol burden, radiative forcing, and climate (Arneth et al., 2009; Bellouin et al., 2011; Chalmers et al., 2012; Gillett and Von Salzen, 2013; Kloster et al., 2009; Lamarque et al., 2011; Leibensperger et al., 2012a, b; Makkonen et al., 2012; Menon et al., 2008; Rotstayn et al., 2013; Shindell et al., 2013; Smith and Bond, 2014; Takemura, 2012; Unger et al., 2009). These studies and their results are summarized in Table 1. In order to have consistent comparisons to the present work, we focus Table 1 on recent studies that used a global climate modeling framework with the RCPs through 2100; hence, studies that may have used other scenarios are not included.

Recently, Levy et al. (2013) used GFDL CM3 model simulations of RCP4.5 to analyze changes in radiative forcing, temperature, and precipitation driven by reductions of aerosol emissions. To isolate the effects of decreasing aerosols, Levy et al. (2013) compared the results of the RCP4.5 simulations with those of another set of simulations, in which all aerosol and precursor emissions were held fixed at 2005 levels throughout the remainder of the 21 st century. The authors found roughly an additional $1{ }^{\circ} \mathrm{C}$ warming and a
$0.1 \mathrm{~mm} \mathrm{day}^{-1}$ increase in precipitation due to the decreasing aerosols in RCP4.5. Here we expand on the results from the Levy et al. (2013) study by estimating the changes in global and regional aerosol burden, climate forcing, and climate response due to projected reductions in aerosol emissions for all four RCPs using an updated version of the same GFDL CM3 model.

We first present the experimental design and the RCP emissions scenarios in Sect. 2. We then go beyond the previous studies described in Table 1 by performing a more exhaustive and robust analysis of the unintended climate consequences of reducing particulate air pollution levels in the future. We also test the robustness of our results using sensitivity simulations with a version of the CM3 model in which aerosol forcing is weakened significantly from its default value (Golaz et al., 2013). We present historical to present day to future results from 1860 to 2100 , focusing first on global changes (Sect. 3) and then on specific regions (Fig. 1) that may be most strongly impacted (Sect. 4). We also compare our results with those from previous studies and examine similarities and differences in the projected aerosoldriven changes in climate variables, climate forcing, and aerosol burden across the various RCPs. Finally, we attempt to connect changes in aerosols with changes in forcing and climate parameters (Sect. 5). Conclusions are presented in Sect. 6. 


\section{Models and simulations}

\subsection{GFDL Climate Model 3}

We use the Geophysical Fluid Dynamics Laboratory Climate Model version 3 (GFDL CM3) in this work. CM3 is a fully coupled chemistry-climate model containing atmosphere, ocean, land, and sea-ice components. We employ the C48 version of the model, which uses a finite-volume cubedsphere horizontal grid consisting of six faces with roughly a $200 \mathrm{~km}$ by $200 \mathrm{~km}$ spatial resolution. Transport of tracers uses the finite volume algorithm of Lin and Rood (1996) with updates as described by Putnam and Lin (2007) and Donner et al. (2011). The vertical grid consists of 48 vertical levels extending from the surface up to about $0.01 \mathrm{hPa}(80 \mathrm{~km})$. Additional details on the model configuration and performance can be found in Donner et al. (2011), Naik et al. (2013), and references therein. Details on the ocean and sea ice model can be found in Griffies et al. (2011).

Anthropogenic emissions of aerosols and their precursors (and emissions or concentrations of all other reactive chemical species) are based on decadal estimates from Lamarque et al. (2010) for the historical period (1860-2000) and from Lamarque et al. (2011) for the RCP projections (20052100). Concentrations of long-lived greenhouse gases are based on Meinshausen et al. (2011). Source-specific emissions are provided for anthropogenic sources (energy use, industrial processes, and agriculture), biomass burning, shipping, and aircraft emissions. Since natural emission sources are not specified by Lamarque et al. (2010), we follow the methodology described by Naik et al. (2013), including emissions of isoprene, soil $\mathrm{NO}_{x}$, lightning $\mathrm{NO}_{x}$, marine primary organic aerosol (POA), DMS, dust, and sea salt. Changes in climate do not feed back on natural emissions except for dust and sea salt, which respond to simulated wind speeds, and lightning $\mathrm{NO}_{x}$, which responds to convective activity. The lack of temperature feedback on biogenic VOC (volatile organic compound) emissions may lead to underestimates of future isoprene or other biogenic VOCs (Heald et al., 2008). Volcanic emissions are as described by Donner et al. (2011).

The tropospheric chemistry component in CM3 is based on Horowitz et al. (2003) with updates from Horowitz (2006) and solves the reaction rate differential equations using an implicit Euler backward method solver with NewtonRaphson iteration. There are 97 total chemical species including 16 aerosol species. Tropospheric chemical reactions, including the $\mathrm{NO}_{x}-\mathrm{O}_{x}-\mathrm{VOC}$ system, are included in the model and fully coupled with the emissions and atmospheric radiation sections of the model. There are a total of 171 gasphase reactions, 41 photolysis reactions, and 16 heterogeneous reactions simulated in the model (Naik et al., 2013). Sulfate aerosols are formed via oxidation of $\mathrm{SO}_{2}$ by the hydroxyl radical $(\mathrm{OH})$, ozone $\left(\mathrm{O}_{3}\right)$, and hydrogen peroxide $\left(\mathrm{H}_{2} \mathrm{O}_{2}\right)$. The oxidation of DMS to sulfate aerosols is also included. DMS emission from the oceans is parameterized based on $10 \mathrm{~m}$ reference-height wind speed but is independent of temperature. Carbonaceous aerosols are modeled in CM3 as primary organic aerosols (POA), secondary organic aerosols (SOAs), and BC. SOAs include both natural and anthropogenic sources. Biogenic terpene oxidation is estimated to provide a directly emitted source of about $30.4{\mathrm{Tg} \mathrm{C} \mathrm{yr}^{-1}}^{-1}$ of SOA and butane oxidation by $\mathrm{OH}$ yields roughly another 9.6 $\mathrm{Tg} \mathrm{C} \mathrm{yr}^{-1}$ (Dentener et al., 2006; Naik et al., 2013; Tie, 2005). Hydrophobic OC and BC aerosols are converted to hydrophilic aerosol with an e-folding time of 1.44 days. Sea salt and mineral dust aerosol are treated with a five-section size distribution ranging from 0.1 to $10 \mu \mathrm{m}$ dry radius.

Aerosol optics in CM3 is based on Mie theory. Lognormal size distributions are assumed for $\mathrm{OC}, \mathrm{BC}$, and sulfate. Sulfate and hydrophilic $\mathrm{BC}$ are assumed to be internally mixed and to undergo hygroscopic growth, while all other aerosols are externally mixed. New to CM3 was the addition of prognostic equations for calculation of cloud droplet number according to the Ming et al. (2006) parameterization, allowing for variable cloud droplet number and radius. The cloud lifetime effect is parameterized as an increase in cloud droplet number (e.g. due to aerosol perturbations) resulting in a decrease in the autoconversion rate, thereby delaying precipitation and increasing cloud lifetime. The derivation of the parameterization is beyond the scope of this paper, but it follows the methodology of Khairoutdinov and Kogan (2000). An autoconversion threshold of $8.2 \mu \mathrm{m}$ is used in CM3. In a given grid box, if the volume-mean cloud droplet radius is less than this threshold, autoconversion is suppressed (Rotstayn, 2000). Sensitivity of the indirect effect to different thresholds in GFDL AM3 is explored in Golaz et al. (2011). Despite being internally mixed with sulfate in the radiation calculation, black carbon is assumed to be externally mixed with soluble species (sulfate, sea salt, OC) for the aerosol activation calculation. Fractions of BC and OC are emitted as hydrophobic (80 and 50\%, respectively) but undergo aging to hydrophilic $\mathrm{BC}$ and $\mathrm{OC}$ with e-folding times of 1.44 and 2.88 days, respectively. Sulfate (treated as pure ammonium sulfate, internally mixed with BC for optics), BC, and OC are assigned individual lognormal size distributions for both the aerosol optics and activation code (Ming et al., 2007). Size-resolved aerosol microphysics are not included in the model due to computational demand. This lack of prognostic aerosol number concentration may bias estimates of the effect of aerosol on clouds. Nonetheless, the aerosol activation scheme has performed well, resulting in reasonable agreement in both droplet size and droplet number concentrations (Donner et al., 2011; Ming et al., 2006, 2007). Donner et al. (2011) showed that CM3 improved upon CM2.1 modelmeasurement evaluation metrics for several aerosol-relevant quantities, including aerosol optical depth, co-albedo, and clear-sky shortwave surface radiation flux. In the current model configuration, neither the radiation nor the activation code currently include nitrate aerosol. At present, nitrate aerosols are estimated to have only contributed marginally 


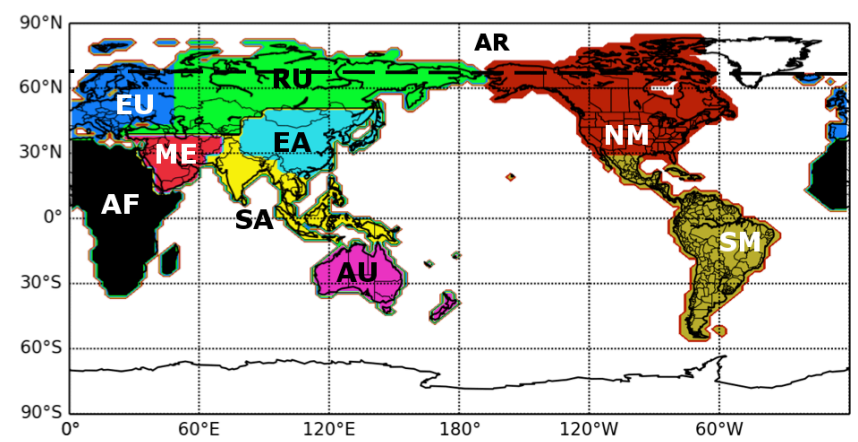

Figure 1. Region definitions for the purposes of this paper. North America (NM), South and Central America (SM), Europe (EU), Russia (RU), East Asia (EA), South Asia (SA), Australia (AU), Africa (AF), Middle East (ME), and Arctic (AR, everything north of the dashed line).

to aerosol radiative forcing and climate effects. As nitrate may become a more significant contributor to aerosol radiative forcing in the future (Bauer et al., 2007; Bellouin et al., 2011; Hauglustaine et al., 2014), the chemical, radiative, and microphysical properties of nitrate aerosol are being incorporated into a new version of the GFDL atmospheric model.

\subsection{RCPs}

The Representative Concentration Pathways (RCPs) contain emissions projections for all long- and short-lived climate forcers, including the aerosol and aerosol precursor species $\mathrm{SO}_{2}$, OC, and $\mathrm{BC}$. The RCPs were featured in the Intergovernmental Panel on Climate Change (IPCC) Fifth Assessment Report (AR5) and are the successors to the Special Report on Emissions Scenarios (SRES). The RCPs include globally gridded projections of emissions of important atmospheric constituents from 2005 to 2100 with extensions to 2300. Using literature and integrated assessment modeling (IAM), representative pathways are selected to fit the individual RCP starting and ending points for radiative forcing. Concentrations and emissions of short- and long-lived climate forcers (including aerosols) are then harmonized (made consistent with base years) and emissions are downscaled (gridded on a latitude-longitude scale). Each of the chosen final pathways are not unique; however, a consortium of experts from the IAM and IPCC communities have selected pathways with desirable qualities such as coverage of the entire literature range and significant spread in concentrations and emissions between the individual pathways. The four pathways include a strong mitigation scenario (RCP2.6), two stabilization scenarios in which radiative forcing stabilizes shortly after 2100 (RCP4.5 and RCP6), and one high emissions/low mitigation scenario (RCP8.5), which current emissions most closely track. The radiative forcing pathways in each RCP are internally consistent with concentrations of both short and long-lived climate forcers, with the exception of dust and nitrate aerosol forcing (Masui et al., 2011; Riahi et al., 2007, 2011; Thomson et al., 2011; van Vuuren et al., $2011 \mathrm{a}, \mathrm{b})$. In addition to representing different GHG emission trajectories, the RCPs implicitly assume air pollution reduction policies in which emissions of reactive pollutants decrease as a function of increasing income, but independently of GHG mitigation levels.

Figure 2 shows the global total emissions (anthropogenic and biomass burning) of $\mathrm{SO}_{2}, \mathrm{BC}$, and $\mathrm{OC}$ for the historical period and for each of the RCPs (see Figs. S1 and S2 in the Supplement for the split between anthropogenic and biomass burning). All four scenarios project strong decreases in globally averaged sulfur dioxide $\left(\mathrm{SO}_{2}\right)$, organic carbon $(\mathrm{OC})$, and black carbon (BC) emissions throughout the 21st century. $\mathrm{SO}_{2}$ emissions, according to the RCPs, have already peaked globally (around 1980) and have been on the decline since, except for a slight uptick in the early 2000s. By $2100, \mathrm{SO}_{2}$ emissions will have decreased from a 2005 level of around 120 to $13-26 \mathrm{Tg} \mathrm{yr}^{-1}$ (RCP2.6 to RCP8.5), about an $80 \%$ decrease. RCP2.6 projects the largest decrease, followed by RCP4.5, RCP6, and RCP8.5. This order is consistent with each RCP's embedded climate policy, since RCP2.6 has the most stringent climate policy and RCP8.5 the least stringent, and many climate policies that curb $\mathrm{CO}_{2}$ emissions can also curb $\mathrm{SO}_{2}$ (e.g. replacement of coal-fired power plants with renewable sources). However, this order does not hold for all species, on either the global and regional scale. Air pollution control also should have an impact on the air pollutant emissions trajectory; however, the assumptions regarding air pollution control were too similar across each of the RCPs to wield noticeable influence (Rogelj et al., 2014). Thus, climate policies (specifically reductions in $\mathrm{CO}_{2}$ emissions from reduced dependence on coal energy) tend to dominate the trend in not only emissions of aerosols and their precursors, but also in aerosol optical depth, radiative forcing, and climate response, as we will show later. Although there is some variability in global $\mathrm{SO}_{2}$ emissions over the course of the time series, the RCPs all converge on a fairly narrow range of endpoints. In particular, RCP6 and RCP2.6 stand out, the former due to an increase in the rate of coal consumption around mid-century (2030-2060) and the latter due to stringent climate policy including the nearly complete phaseout of nonCCS (carbon capture and storage) coal energy by roughly 2050 (Masui et al., 2011; van Vuuren et al., 2011b). The increase in coal energy projected by RCP6 is a surprising feature that is not present in the other RCPs. As a result, $\mathrm{SO}_{2}$, $\mathrm{BC}$, and $\mathrm{OC}$ emissions in RCP6 are higher relative to the other RCPs over roughly the same time period in (Fig. 2). $\mathrm{SO}_{2}$ emissions briefly increase in absolute terms over a short period mid-century in RCP6, which drives higher sulfate burdens, larger (negative) aerosol direct and indirect forcings, and noticeable changes in climate response, as we will show in the following sections. The narrow range for emissions of air pollutants and their precursors (e.g. $\mathrm{SO}_{2}$ ) has been attributed to similar air pollution policy assumptions in each 

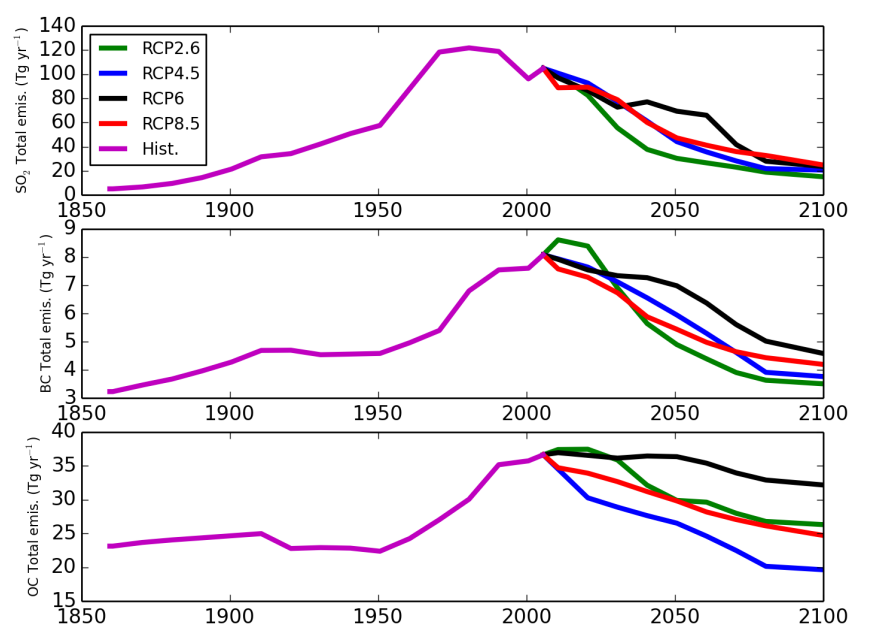

Figure 2. Global total emissions (anthropogenic + biomass burning) of sulfur dioxide $\left(\mathrm{SO}_{2}\right)$, black carbon $(\mathrm{BC})$, and organic carbon (OC) from 1860 to 2100 . Historical emissions are colored in magenta, RCP2.6 in green, RCP4.5 in blue, RCP6 in black, and RCP8.5 in red.

RCP. New scenarios that strive to span the entire literature range for air pollutants in addition to greenhouse gases are undergoing development (Rogelj et al., 2014).

$\mathrm{BC}$ emissions (middle panel in Fig. 2) increased from preindustrial times and continue to increase in RCP2.6, peaking around 2010. RCP4.5, RCP6 and RCP8.5 all peak around 2005 (i.e. the beginning of the RCP projections) and decrease continuously until 2100 . Present-day values of $\mathrm{BC}$ emissions are $8.5 \mathrm{Tg} \mathrm{yr}^{-1}$. By $2100, \mathrm{BC}$ emissions are projected to range from less than $3.3 \mathrm{Tg} \mathrm{yr}^{-1}$ according to $\mathrm{RCP} 2.6$ up to $4.3 \mathrm{Tg} \mathrm{yr}^{-1}$ in RCP6. Here, the expected order seen in the $\mathrm{SO}_{2}$ emissions reductions is not observed, but $\mathrm{BC}$ emissions do also converge on a relatively narrow range of endpoints.

Emissions of OC, sometimes co-emitted with BC, have a similar trajectory (bottom panel Fig. 2). The main source of OC emissions in the RCPs is biomass burning, which makes up about $60 \%$ of the total emissions of OC in present day. RCP2.6 OC emissions continue to increase in the early 21 st century, peaking around 2020. Emissions of OC in RCP4.5 drop rapidly, due to the strong decrease in cropland area and increase in forested area projected by RCP4.5 (in other words, a decrease in biomass burning as a means to clear cropland), a trend that is mostly unique to RCP4.5 (van Vuuren et al., 2011a; Thomson et al., 2011). OC emissions in RCP6 remain high throughout the 21st century due to the land use assumptions embedded in RCP6, which includes shifts to larger amounts of burning to clear land for crops. $\mathrm{CO}_{2}$ fertilization also plays a role in the increased emissions, as higher $\mathrm{CO}_{2}$ levels can increase biomass growth and increase the amount available to be burned (Kato et al., 2011). Compared to $\mathrm{SO}_{2}$ and $\mathrm{BC}$, the variability and range of emissions endpoints across the different RCPs is much wider, ranging from $20 \mathrm{Tg} \mathrm{yr}^{-1}$ in RCP4.5 in 2100 to about $32 \mathrm{Tg} \mathrm{yr}^{-1}$ in RCP6. The final order of each RCP's global total OC emissions is different from that of both the $\mathrm{BC}$ and $\mathrm{SO}_{2}$ final order, highlighting the difficulty in comparison between different RCPs. In particular, the lack of climate policy in RCP8.5 has little influence on $\mathrm{OC}$ and $\mathrm{BC}$ emissions in comparison to $\mathrm{SO}_{2}$.

\subsection{Simulations}

We conduct simulations using GFDL CM3 to evaluate the role of changing aerosol emissions on aerosol optical depth (AOD), aerosol radiative forcing, and climate response. Table 2 summarizes the simulations performed. A series of RCP simulations (denoted RCPx.x where $\mathrm{x} . \mathrm{x}=2.6,4.5$, etc.) were run from 2006 to 2100 in which the RCP emissions scenarios were used for future aerosol, greenhouse gas, and other reactive species emissions or concentrations. Another series of simulations were run using the RCPs, but with the anthropogenic and biomass burning emissions of $\mathrm{SO}_{2}$, OC, and BC held constant at 2005 levels. All other inputs, including greenhouse gases, were kept the same as in the full RCP scenarios. We denote these fixed emission simulations as RCPx.x_2005AER, where the 2005AER signifies fixed aerosol and aerosol precursor emissions at 2005 levels. Each of the RCPx.x and RCPx.x_2005AER simulations were run as a three-member ensemble, each initialized with different initial conditions, provided by another three-member historical ensemble (1860-2005) of GFDL CM3. The RCP4.5 and RCP4.5_2005AER simulations are not scientifically different from those presented by Levy et al. (2013); however, our simulations were run with a newer model version, which included some minor updates. We calculate the aerosol-induced climate response as the difference between the two sets (RCPx.X-RCPx.x_2005AER). Unless otherwise specified, all results presented are ensemble means. Meteorological factors, such as increasing temperatures, changes in atmospheric circulation and stability, and changes in precipitation will also induce changes in aerosol concentrations (Dawson et al., 2007; Jacob and Winner, 2009; Leibensperger et al., 2012a; Pye et al., 2009; Tai et al., 2012, 2010). The influences of greenhouse-gas driven meteorological changes are included in both our RCPx.x and RCPx.x_2005AER simulations. Our methodology of running the RCPx.x_2005AER simulations for the full 21 st century allows us to simulate the climatedriven effects on aerosol abundance (AOD and concentration). Additionally, taking the difference between RCPx.x and RCPx.x_2005AER isolates the changes in aerosols (and climate response) resulting from emissions reductions alone, separate from the influence of well-mixed GHG-driven climate changes. While these RCPx.x_2005AER simulations (or analogues) were performed in some past studies, to our knowledge this is the first study to present the results from 
Table 2. List of simulations.

\begin{tabular}{|c|c|c|c|}
\hline & RCP simulations & $\begin{array}{l}\text { RCP Fixed emis. } \\
\text { simulations }\end{array}$ & $\begin{array}{l}\text { RCP Fixed SST } \\
\text { simulations }\end{array}$ \\
\hline \multirow{5}{*}{ Simulation name } & $\mathrm{RCP} 2.6$ & RCP2.6_2005AER & RCP2.6_RFP \\
\hline & $\mathrm{RCP} 4.5$ & RCP4.5_2005AER & RCP4.5_RFP \\
\hline & RCP6 & RCP6_2005AER & RCP6_RFP \\
\hline & $\mathrm{RCP} 8.5$ & RCP8.5_2005AER & RCP8.5_RFP \\
\hline & CM3w_RCP8.5* & CM3w_RCP8.5_2005AER* & RCP_1860 \\
\hline Aerosol setup & Time-varying & $\begin{array}{l}\mathrm{SO}_{2}, \mathrm{OC}, \mathrm{BC} \text { emissions fixed } \\
\text { at } 2005 \text { levels }\end{array}$ & $\begin{array}{l}\text { Time-varying, aerosol } \\
\text { forcing only }\end{array}$ \\
\hline GHG & Time-varying & Time-varying & Time varying \\
\hline
\end{tabular}

* Simulation uses configuration with weaker aerosol effective radiative forcing (see Sect. 2.3).

such simulations for all four of the RCPs in a consistent framework.

In order to estimate aerosol effective radiative forcing, we ran additional non-coupled, atmospheric component-only simulations (AM3) in which sea surface temperatures (SST) were held constant at the 1981-2000 climatological values. Simulations were run in which the only climate forcings were aerosol emissions changes from present day through 2100 , allowing us to calculate the aerosol forcing by differencing radiative fluxes with a control simulation using 1860 emissions and the same climatological SSTs. Using the fixed SST approach allows us to estimate the radiative response to "fast" adjustments (time scale of a few years or less) to the climate system due to a forcing agent (e.g., aerosols) in addition to the full response to the forcing agent itself. This method accounts for the indirect effects of aerosols, including the cloud lifetime effect and the cloud albedo effect. This type of fixed-SST calculation has been referred to as the "radiative flux perturbation" (Lohmann et al., 2010) or "effective radiative forcing" (Myhre et al., 2013). This series of simulations are denoted RCPx.x_RFP for the aerosol-only simulations and RCP_1860 for the control simulation. This pair of simulations is only used for the radiative forcing calculations, while the coupled runs described above provide $\mathrm{AOD}$ and climate response estimates.

As reported in Levy et al. (2013), the present-day aerosol effective radiative forcing (ERF) in $\mathrm{CM} 3$ of -1.7 to $-1.8 \mathrm{~W} \mathrm{~m}^{-2}$ falls close to the upper bound of the $90 \%$ confidence interval, $-1.9 \mathrm{~W} \mathrm{~m}^{-2}$, set by the IPCC. To test the robustness of our results, we conduct additional experiments using an alternate model configuration with weaker presentday aerosol effective radiative forcing. With a lower "starting point", future decreases in the magnitude of aerosol forcing will also be reduced, likely resulting in a reduced climate response. We use the "CM3w" experiment described by Golaz et al. (2013), in which cloud parameters, most notably the autoconversion threshold, are tuned to produce the desired changes in climate forcing. In this ver- sion, the present-day aerosol effective radiative forcing is around $-1.0 \mathrm{~W} \mathrm{~m}^{-2}$. To achieve this effect, we adjust the autoconversion threshold from its default value of 8.2 to $6.0 \mu \mathrm{m}$. Since a lower autoconversion threshold is not consistent with observations (Rotstayn, 2000), we emphasize that this change is employed only as a means to test our results with a lower magnitude present-day aerosol ERF, and is not meant to produce a more scientifically accurate model version. The CM3w run is initialized from a historical run of $\mathrm{CM} 3 \mathrm{w}$, using one ensemble member each for RCP8.5 and RCP8.5_2005AER. These simulations are denoted CM3w_RCP8.5 and CM3w_RCP8.5_2005AER.

\section{Global analysis}

We first focus our analysis on area-weighted global means ranging from pre-industrial times to 2100 . We analyze aerosol optical depth (sulfate, BC, and OC), aerosol climate forcing (direct and indirect), and climate response (temperature, precipitation rate, liquid water path, and effective cloud droplet radius). In subsequent sections, the analysis is extended to examine spatial distributions and mean changes over specific regions. Past, present, and future trends in global aerosol optical depth can be found in the Supplement Sect. S2 as well as Figs. S3 and S4. In short, AOD trends are well correlated with emissions trends, with correlation coefficients ranging from 0.7 to 0.9 for each species and each RCP (not shown) globally averaged, and 0.9 or greater over continental source regions. By 2100, sulfate AOD globally is projected to decrease by $50 \%$ from 2005 levels in RCP2.6, $40 \%$ in RCP4.5 and RCP6, and $31 \%$ in RCP8.5 (see Supplement). Figure S3 shows the RCPx.x_2005AER fixed emissions simulations (dashed lines) along with the RCPx.x decreasing emissions runs (solid lines) indicating that in the absence of emissions changes, future climate changes cause AOD to increase globally for each of the RCPs. However, this climate driven effect is small compared to the substantial de- 
crease in AOD from emissions reductions (compare dashed and solid lines in Fig. S3).

\subsection{Aerosol forcing}

\subsubsection{Aerosol direct and indirect forcing}

Future changes (mostly decreases) in aerosol emissions and aerosol amount and optical depth lead to changes in Earth's radiative balance. Figure 3 shows the globally averaged total top-of-atmosphere (TOA) aerosol effective radiative forcing (direct and indirect) for the historical period and four RCP projections using the standard CM3 runs. From 1860 until present day, the increasing abundance of atmospheric aerosols led to a larger (more negative) aerosol forcing, peaking near present day. Preindustrial to present day aerosol forcing simulated by $\mathrm{CM} 3$ is about $-1.8 \mathrm{~W} \mathrm{~m}^{-2}$. This large negative forcing has offset or "masked" some of the positive forcing from greenhouse gases. Although the net forcing is still positive, without the large increase in the 20th century of aerosol emissions, the net positive forcing would be much larger. As we discuss in Sect. 3.2, this masking by aerosols of the positive, greenhouse gas warming has important implications for climate. During the 21 st century, the large decreases in global aerosol and aerosol precursor emissions projected by the RCPs cause aerosol forcing to decrease in magnitude (become less negative). As discussed in Sect. 2.3, we also use a version of CM3 with a reduced present-day aerosol ERF, in order to test the robustness of our results to the magnitude of aerosol forcing. We present climate response results for these simulations in subsequent sections but did not run fixed-SST simulations with this adjusted version of CM3, hence we do not present forcing values associated with these runs.

As in many of the other trends shown thus far, there is limited spread in the various RCP projections of global aerosol effective radiative forcing (Fig. 3). For the 209621005 -year average, the effective forcing (relative to 1860) is $-0.21 \mathrm{~W} \mathrm{~m}^{-2}$ for RCP2.6, $-0.32 \mathrm{~W} \mathrm{~m}^{-2}$ for RCP4.5, $-0.46 \mathrm{~W} \mathrm{~m}^{-2}$ for RCP6, and $-0.53 \mathrm{~W} \mathrm{~m}^{-2}$ for RCP8.5. RCP2.6 has the largest decrease in magnitude of aerosol forcing over the century, followed by RCP4.5, RCP6, and RCP8.5, which is the expected order according to each RCP's underlying climate policy. For example, reduction of coal energy usage, a GHG mitigation policy featured in the RCPs, also reduces the amount of $\mathrm{SO}_{2}$ emissions. As a result, total aerosol forcing trends and the end-of-century rank order for each of the RCPs can be traced back ultimately to the energy and climate mitigation policy. Furthermore, sulfate is the main contributor to the aerosol direct and indirect forcing trend for all RCPs, due to its optical properties as well as large CCN activity (hygroscopicity). Therefore, energy policies that affect sulfate will have a magnified effect on aerosol direct and indirect forcing. On the other hand, the direct climate effects of $\mathrm{BC}$ and $\mathrm{OC}$ have been reported to offset each other (OC being the negative forcing, $\mathrm{BC}$ positive) in previ-

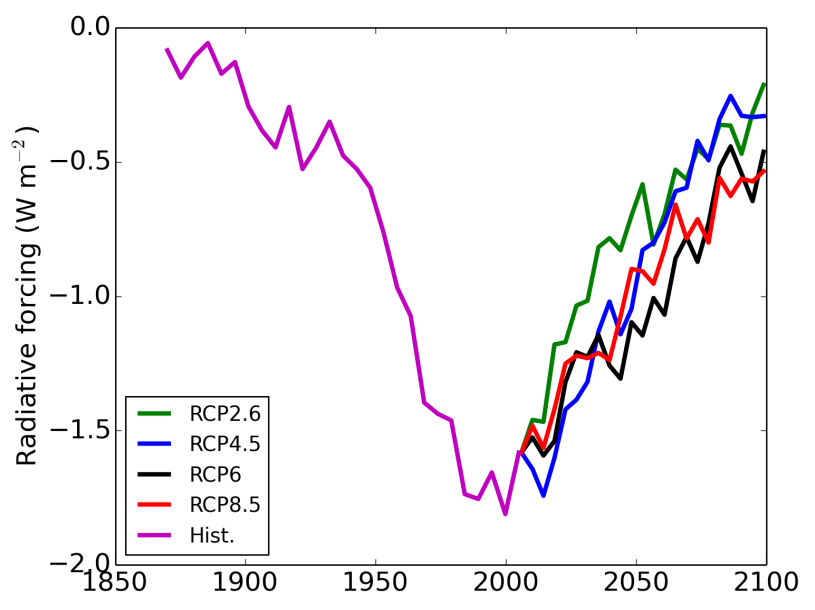

Figure 3. Globally averaged historical and future time series of topof-atmosphere effective radiative forcing $\left(\mathrm{W} \mathrm{m}^{-2}\right)$ from emissions of aerosols and their precursors alone.

ous studies with CM3 (Levy et al., 2013), and that is the case in this work as well. RCP6 projects the smallest decrease in magnitude of aerosol forcing for much of the middle part of the century (2045-2075), despite passing RCP8.5 eventually. This is consistent with both the emissions and AOD trajectories for RCP6. RCP6 projects mid-century increases in coal for energy supply globally (Masui et al., 2011), which is visible not only in the emissions and AOD trends as described elsewhere but also the aerosol forcing trends.

\subsubsection{Comparison to 2005 levels}

The large decrease in the magnitude of aerosol forcing from present day to 2100 represents a large positive forcing for 2100 relative to present. The globally averaged forcing changes from present day to year 2100 for each RCP scenario are tabulated in Table 3. In order to have a consistent basis for comparison across the four RCPs and to account for noise in the trends, the beginning and end of century forcing values were taken as 5-year averages, 2000-2004 and 2096-2100. The amount of unmasked aerosol forcing follows the order expected according to each RCP's climate policy (as explained above), as is the case with $\mathrm{SO}_{2}$ emissions (Fig. 2). For RCP2.6, the forcing increases by $1.37 \mathrm{~W} \mathrm{~m}^{-2}$ from 2000 to 2100 . RCP8.5 represents the lower part of the range at $1.05 \mathrm{~W} \mathrm{~m}^{-2}$. An additional positive forcing of at least $1 \mathrm{~W} \mathrm{~m}^{-2}$ would have major climate implications. For comparison, the $2100 \mathrm{RCP} 8.5 \mathrm{CO}_{2}$ forcing is about $5 \mathrm{~W} \mathrm{~m}^{-2}$ (Myhre et al., 2013). Thus, the resulting positive forcing from the decrease in aerosol emissions by 2100 is projected to be more than $20 \%$ of the forcing of $\mathrm{CO}_{2}$ in 2100 .

As a caveat, our reported aerosol effective radiative forcing values may be a overestimate due to the tendency of the GFDL CM3 model to overstate the cloud lifetime effect, thus inflating the magnitude of our positive forcing due to aerosol 
Table 3. Global average difference in aerosol optical depth (AOD), forcing (RF), temperature $(T)$, total precipitation rate $(P)$, liquid water path (LWP), and cloud droplet effective radius $\left(R_{\text {eff }}\right)$ due to aerosol emissions reductions at the end of the 21 st century (2096-2100 average). Values represent differences between RCP simulations and fixed 2005 simulations (base cases) (RCPx.X-RCPx.x_2005AER). RF values represent the difference between 2100 and 2006 total aerosol forcing.

\begin{tabular}{lrrrrrrrr}
\hline & $\begin{array}{r}\mathrm{SO}_{4} \\
\mathrm{AOD}\end{array}$ & $\begin{array}{r}\mathrm{BC} \\
\mathrm{AOD}\end{array}$ & $\begin{array}{r}\mathrm{OC} \\
\mathrm{AOD}\end{array}$ & $\begin{array}{r}\mathrm{RF} \\
\left(\mathrm{W} \mathrm{m}^{-2}\right)\end{array}$ & $\begin{array}{r}T \\
(\mathrm{~K})\end{array}$ & $\begin{array}{r}P \\
\left(\mathrm{~mm} \mathrm{day}^{-1}\right)\end{array}$ & $\begin{array}{r}\mathrm{LWP} \\
\left(\mathrm{g} \mathrm{m}^{-2}\right)\end{array}$ & $\begin{array}{r}R_{\text {eff }} \\
(\mu \mathrm{m})\end{array}$ \\
\hline RCP2.6 & -0.034 & -0.0018 & -0.0055 & 1.37 & 0.97 & 0.080 & -0.555 & 0.584 \\
RCP4.5 & -0.033 & -0.0017 & -0.0081 & 1.25 & 0.81 & 0.078 & -0.870 & 0.603 \\
RCP6.0 & -0.032 & -0.0011 & -0.0005 & 1.12 & 0.72 & 0.082 & -0.502 & 0.541 \\
RCP8.5 & -0.035 & -0.0014 & -0.0057 & 1.05 & 1.04 & 0.093 & -0.748 & 0.585 \\
CM3w_RCP8.5* & - & - & - & $\sim 0.5$ & 0.51 & 0.048 & -0.218 & 0.472 \\
\hline
\end{tabular}

* Simulation uses configuration with weaker aerosol effective radiative forcing (see Sect. 2.3).

decline (Levy et al., 2013). We test the robustness of our results with respect to the magnitude of aerosol forcing using $\mathrm{CM} 3 \mathrm{w}$, a version of the model with much weaker present-day ERF (see Sect. 2.3). In a multimodel evaluation of proxies for the aerosol indirect effects (both albedo and lifetime) against satellite observations, a prototype version of AM3 was found to be one of several models overestimating the strength of the relationship between cloud liquid water path (LWP) and aerosol optical depth (defined as sensitivity of LWP to AOD perturbations) (Quaas et al., 2009). Ratios for AM3 were roughly an order of magnitude larger than observations over land and ocean; however, other models performed just as poorly if not worse (all models overestimate the land ratio by at least a factor of two). Generally, a positive correlation is expected between aerosol optical depth and cloud liquid water path, since the increase in cloud droplet number concentration leads to a delay in autoconversion rate, increasing cloud lifetime and cloud liquid water path. However, some studies have found potential for a negative correlation due to a drying effect from increased entrainment of air above the clouds (Ackerman et al., 2004). Thus, the autoconversion parameterization in AM3, which is a simple implementation that does not address the effect of increased entrainment and other confounding issues, could conceivably be driving an overestimate in the cloud lifetime effect and thus the indirect effect as a whole.

\subsection{Climate response}

\subsubsection{Global historical and future trends}

The emission reductions and aerosol forcing trends discussed earlier are expected to have significant effects on future climate. Figure 4 shows the $1860-2100$ globally averaged time series for temperature, precipitation rate, liquid water path, and effective cloud droplet radius for the historical, RCPx.x ensemble mean (solid lines), and RCPx.x_2005AER ensemble mean (dashed lines). Since the RCPx.x simulations contain all climate-forcing agents (compared to the aerosol differences we will discuss later), greenhouse gases have a large
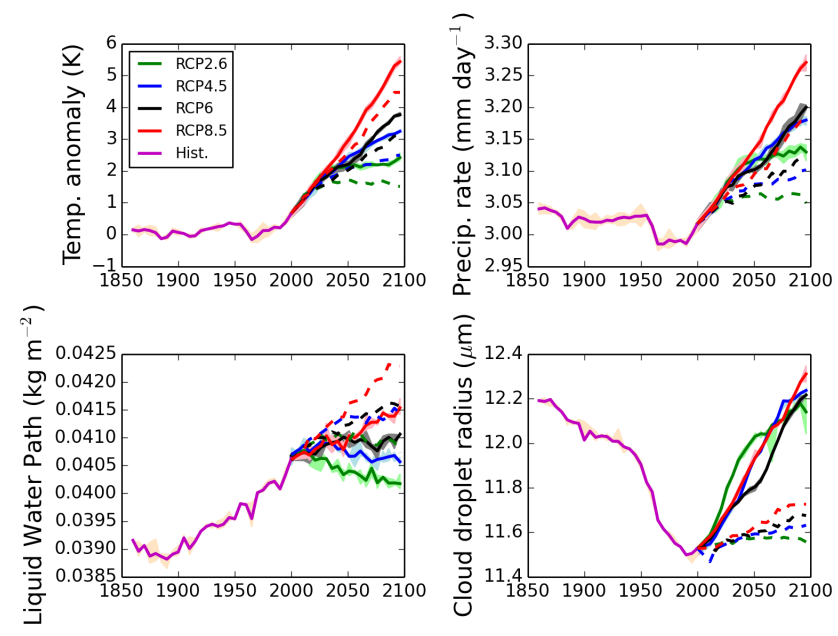

Figure 4. Globally averaged trend in climate response variables from 1860 to 2100 . Upper left: surface air temperature (K), upper right: total precipitation rate $\left(\mathrm{mm} \mathrm{day}^{-1}\right)$, bottom left: liquid water path $\left(\mathrm{kg} \mathrm{m}^{-2}\right)$, bottom right: effective cloud droplet radius $(\mu \mathrm{m})$. Shaded light colors represent the range of the three ensemble members, solid lines are the ensemble means for the RCPx.x time-varying simulations. Dashed lines are the ensemble means for the RCPx.x_2005AER control simulations (ensemble range not shown).

influence. Temperature anomaly (relative to $1881-1920$ average) is projected to range from about $2-5 \mathrm{~K}$ by 2100 , mostly due to anthropogenic greenhouse warming. Likewise, global precipitation rates will increase, which will be shown in the following section to result partially from an increase in greenhouse gases and a decrease in aerosol emissions. Precipitation rate in the historical simulation had a significant decrease around 1950-1970; this time frame coincides with a doubling in the global anthropogenic $\mathrm{SO}_{2}$ emissions (Fig. 2). Liquid water path (LWP) (Fig. 4, bottom left) steadily increases from 1860 to present day, then has four very different trajectories in the RCP future projections. The higher temperatures of RCP8.5 and RCP6 most likely lead to LWP in- 
creases, and the order of LWP values in each RCP in 2100 is consistent with the amount of temperature increase. Effective cloud droplet radius (calculated over the top two units of optical depth for liquid clouds, consistent with the Moderate Resolution Imaging Spectroradiometer (MODIS) algorithm (Donner et al., 2011; Guo et al., 2014; King et al., 2003) and weighted by cloud fraction) decreases steadily from 1950 to present day, also due to the large increase in aerosol emissions. Since many ultrafine particles are anthropogenic in nature (e.g., sulfate), an increase in their emission drives down the global average cloud droplet effective radius, since smaller sized aerosols are effective $\mathrm{CCN}$ that are likely to activate into cloud droplets. Likewise, with aerosol emissions declining in the 21 st century, cloud droplet radius increases across all of the RCPs.

\subsubsection{Climate response to aerosol forcing}

As with aerosol optical depth, taking the difference between the time-varying simulations discussed in Sect. 3.3.1 and the fixed aerosol emission simulations (RCPx.XRCPx.x_2005AER), we deduce the impacts on climate driven solely by the aerosol emissions reductions for each year of each future emission scenario. Figure 5 presents the globally averaged differences for temperature, precipitation rate, LWP, and cloud drop effective radius resulting from aerosol emission reductions in the RCPs (also tabulated in Table 3 for a 5-year average of 2096-2100 only). Additionally, the dashed lines in Fig. 4 represent the fixed emission ensemble means (RCPx.x_2005AER), thus comparing these with the values from the time-varying emissions ensemble (solid lines) gives an estimate of the aerosolunmasking-driven contribution to the climate response. The projected global temperature increase due to aerosol emissions reduction alone ranges from 0.72 to $1.04 \mathrm{~K}$ in the standard CM3 with RCPs, compared to 2005 temperature levels. This is a significant fraction of the total temperature increase by 2100 (including greenhouse gas induced warming) of $1-5 \mathrm{~K}$ across the RCPs (compare dashed and solid lines in Fig. 4). However, in the reduced-aerosol-forcing run with RCP8.5 (CM3w_RCP8.5), the globally averaged temperature increase due to aerosol decreases is only about $0.5 \mathrm{~K}$, half of that in RCP8.5 with standard CM3. This result indicates that the projected climate response to aerosol decreases throughout the 21 st century depends strongly on the magnitude of the present-day aerosol ERF, as a weaker ERF $\left(\sim-1 \mathrm{~W} \mathrm{~m}^{-2}\right)$ can cut the global temperature response in half. This is discussed in more detail in Sect. 4.1.3 and shown in Figs. 7 and 8. The impact of the aggressive phaseout of coal as an energy source in RCP2.6 can be seen from about 2020-2050 with a strong increase in aerosol-driven temperature change. Likewise, the mid-century rise in coal use in RCP6 shows up as a decline in what is an otherwise consistent temperature increase throughout the century (Fig. 5). RCP4.5 and RCP8.5, on the other hand, have a steadier tem-
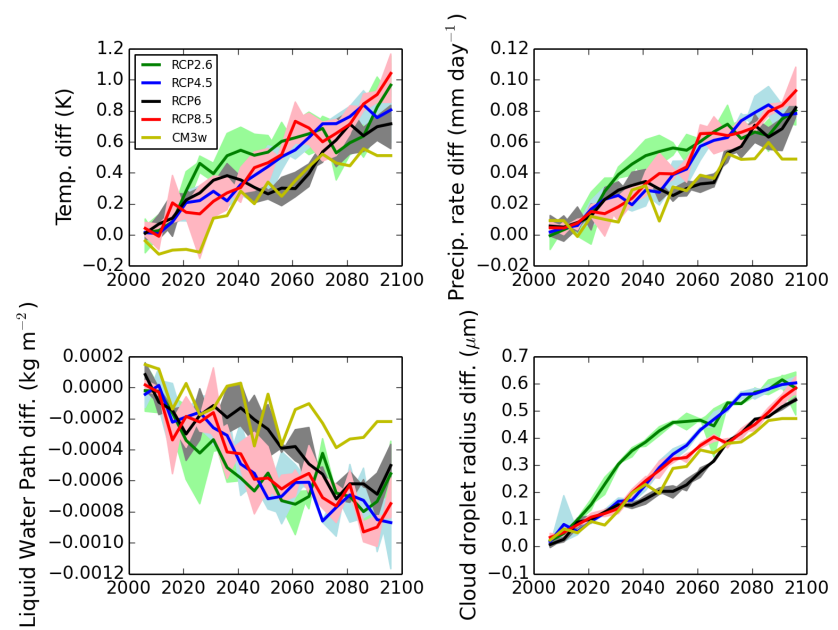

Figure 5. Globally averaged trend in climate variable anomalies from 2006-2100. Values represent differences between the projected RCP simulations and the fixed 2005 aerosol emissions case (RCPx.x-RCPx.x_2005AER). Upper left: surface air temperature $(\mathrm{K})$, upper right: total precipitation rate $\left(\mathrm{mm} \mathrm{day}^{-1}\right)$, lower left: liquid water path (LWP) $\left(\mathrm{kg} \mathrm{m}^{-2}\right)$, lower right: effective cloud droplet radius at cloud top $(\mu \mathrm{m})$. Shaded light colors represent the range of the three ensemble members, solid lines are the ensemble means. Yellow lines represent the CM3w_RCP8.5 run.

perature increase that lacks the same noticeable features. There is a significant amount of overlap in climate response from decreasing aerosols among the RCPs throughout the entire century, especially considering the full range of the ensemble members of each simulation. This suggests that despite large differences in many facets of the individual RCPs (e.g., climate mitigation policies, emissions trajectories, land use), the temperature response to decreasing aerosols is relatively homogenous.

Although global precipitation rate (Fig. 5 upper right) is mainly controlled by the tropospheric energy balance (Ming et al., 2010), precipitation is linked to aerosols on the local scale, since aerosols serve as seeds for cloud droplet formation and the number and size of the cloud droplets influence the distribution and timing of precipitation. Additionally, aerosols can impact precipitation in other ways, including by changing atmospheric dynamics and circulation patterns, changing atmospheric heating rates, and changing the surface energy balance. We find increases of $0.08-0.09 \mathrm{~mm} \mathrm{day}^{-1}$ (up to $3 \%$ of 2005 precipitation levels) are projected to result from the aerosol decrease in the four RCPs run with standard CM3, again representing a very narrow range of climate endpoints despite the differences among the scenarios. The estimated increase of precipitation is reduced to only about a $0.04 \mathrm{~mm} \mathrm{day}^{-1}$ increase by the end of the $21 \mathrm{st}$ century in the CM3w_RCP8.5 runs with weaker present-day aerosol ERF. Nonetheless, since the total precipitation rate increase from all forcings ranges from $0.11-0.25 \mathrm{~mm} \mathrm{day}^{-1}$ (Fig. 4), 
these aerosol driven changes are significant (discussed more in Sect. 4.1.3 and shown in Figs. 7 and 8).

Liquid water path differences over time are shown for each of the RCPs in the lower left panel of Fig. 5. As aerosol concentrations decrease, LWP also decreases; in other words, aerosols and LWP are positively correlated. This is essentially the cloud lifetime effect acting in the opposite direction: increased aerosols cause cloud droplet concentrations to increase leading to a decrease in the autoconversion rate, which hinders precipitation formation and increases cloud lifetime and cloud liquid water path (Albrecht, 1989). The decline in aerosol emissions leads to a decrease in LWP in all of the standard CM3 runs with the RCPs, around 0.5$1.0 \mathrm{~g} \mathrm{~m}^{-2}$ or $2 \%$ of 2005 levels. Accounting for the ensemble member range (shaded areas), the LWP decline in each of the RCPs is remarkably similar. As is the case with radiative forcing, temperature, and precipitation, the annual trends in the LWP values also follow the underlying RCP energy use trajectories. In particular, a rebound around 2040 in LWP in RCP6 can be seen in the bottom left of Fig. 5, analogous to the temperature decrease in RCP6 due to an increase in coal energy usage rate and ultimately aerosol and precursor emissions. LWP decreases in CM3w_RCP8.5 are remarkably smaller, only about $20-40 \%$ of the decreases standard CM3 RCP runs. With a lower autoconversion threshold, the amount of liquid water held in clouds is decreased, resulting in the smaller change in CM3w_RCP8.5 shown in Fig. 5c.

With decreasing aerosols, effective cloud drop radius may increase due to the loss of smaller-sized and more numerous anthropogenic ultrafine aerosol, leaving natural aerosols (such as sea spray, which in general are fewer in number and much coarser in size) to form cloud droplets. Across the four RCPs, the globally averaged increase in cloud drop effective radius due to decreasing aerosols ranges from 0.54 to $0.60 \mu \mathrm{m}$ (Fig. 5, Table 3). The increase due to all forcings ranges from about $0.60-0.80 \mu \mathrm{m}$ (Fig. 4). As expected, the increases in cloud droplet effective radius due to aerosol reductions make up a large fraction of the all-forcing increases. Cloud droplet effective radius trends follow energy usage and emissions trends in each of the RCPs very closely, with the results from the individual RCPs being quite distinct from one another through most of the century before slightly converging around 2100. Cloud droplet radius does not appear to be significantly affected by the lower autoconversion parameterization, as the differences between RCP8.5 with standard CM3 and RCP8.5 with CM3w are minimal.

\section{Spatial distribution and regional analysis}

Emissions of aerosols and aerosol precursors are highly heterogeneous in space. As expected, the changes of AOD, radiative forcing, and climate change in response to projected future emission changes also exhibit strong spatial structure. In this section, we first examine the spatial distributions of the changes in AOD and climate response, and then consider the average responses over two key source regions, East Asia and North America. Judging by historical emissions over the last few years since the RCPs were developed, concentrations of GHG in the atmosphere are tracking at or even above the trajectory predicted by RCP8.5 (the highest emission scenario), so we will focus mainly on that scenario (Peters et al., 2012; Sanford et al., 2014).

\subsection{Spatial distributions}

\subsubsection{Aerosol optical depth}

Figure 6 shows the RCP8.5 aerosol optical depth $(550 \mathrm{~nm})$ differences (RCP8.5 - RCP8.5_2005AER) for the end of the 21st century (2096-2100 average) for sulfate, BC, OC, and total AOD. Corresponding results for the other three RCPs can be found in Figs. S6-S8 of the supplemental information. Strong reductions in AOD are simulated over most continental regions, including North America, Europe, and Asia. This coincides with the strong $\mathrm{SO}_{2}$ emissions decreases projected by RCP8.5 (and all RCPs) for much of the world. East and South Asia have the largest and most widespread decreases in AOD for all species. However, there are a few regions in which emissions changes are projected to increase sulfate AOD by 2100. Africa has noticeable areas of sulfate AOD increase, which can be explained by RCP8.5 projected increases in emissions at a few locales in this region (see Fig. S5 in the Supplement). Parts of Africa are expected to industrialize and grow throughout the rest of the century and utilize its natural fossil fuel resources (Masui et al., 2011; Riahi et al., 2007). Similarly, RCP8.5 projects sulfate AOD increases for Indonesia, a region that is also projected to industrialize and experience an increase in biomass burning, resulting in elevated emissions of $\mathrm{SO}_{2}, \mathrm{BC}$, and OC. There are also a few areas of increase over the tropical Pacific and Atlantic oceans for $\mathrm{OC}$ and $\mathrm{SO}_{2}$ which are not caused by emissions increases (see Fig. S5) and instead result from meteorological changes, specifically a decrease in effectiveness of wet deposition removal of sulfate and OC. Since precipitation is increasing along with sulfate and OC aerosol optical depth, a decrease in the efficacy of wet deposition is implied. Although we do not have wet deposition fluxes archived in the model output, we note that using the same model, Fang et al. (2011) confirmed this relationship between increasing precipitation and decreasing wet deposition removal effectiveness. Using an idealized soluble tracer, the authors found that as climate warms, wet deposition of soluble pollutants decreases due to the simulated decreases in large-scale precipitation frequency. In the future, moderate and light precipitation is projected to occur less frequently, whereas heavy precipitation occurs more frequently. Since wet deposition does not depend on strength of precipitation events (i.e. same wet deposition flux for heavy or light rain), the decrease in frequency of light precipitation events leads to less wet de- 

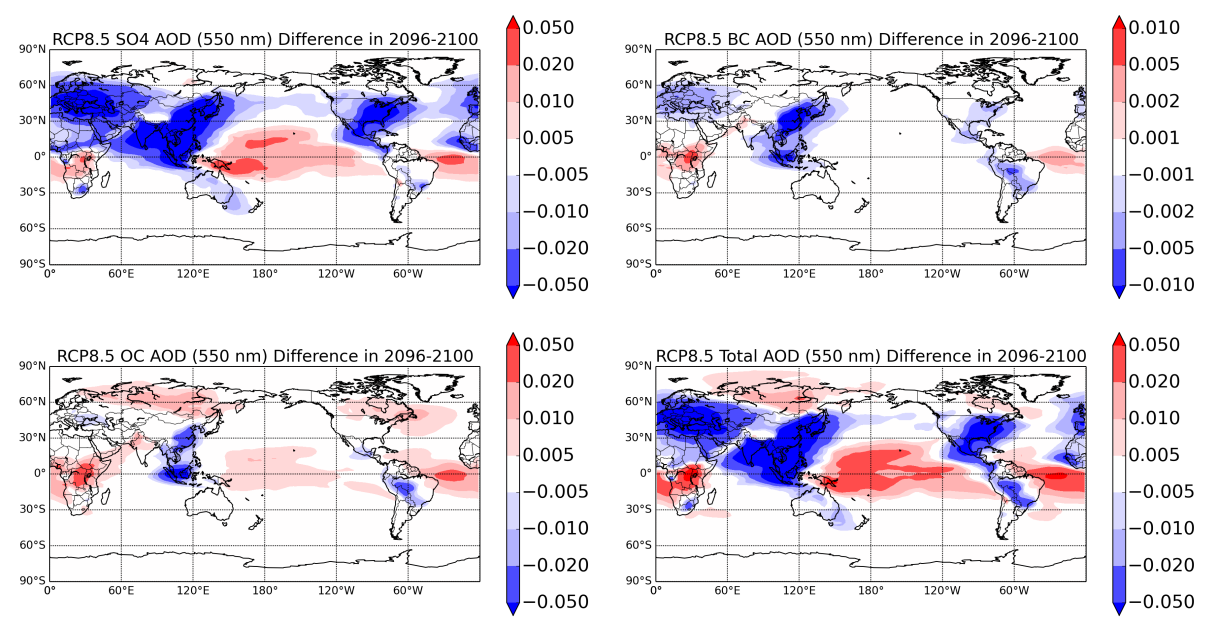

Figure 6. Anomalies in aerosol optical depth for 2096-2100 5-year average for RCP8.5. Values represent differences between the projected RCP aerosol optical depth and the fixed 2005 aerosol emissions case (RCP8.5-RCP8.5_2005AER). Note the different scale for BC AOD.

position flux in the future and thus increases in AOD (Fang et al., 2011).

Asian BC and OC AOD decreases by 2100 are much larger than those in North America or Europe (Fig. 6). Some increases are again projected in Africa. BC and OC biomass burning emissions on average in Africa are generally expected to maintain current levels or decline slightly; however, in this particular region of Africa (mostly in Democratic Republic of the Congo and the Central African Republic), biomass burning emissions of $\mathrm{OC}$ and $\mathrm{BC}$ are projected to rise (not shown, see Fig. S5 in the Supplement). In particular, combustion and biomass burning emissions in Africa are expected to increase rapidly in the near-term (Liousse et al., 2014). The total AOD difference in 2100 for RCP8.5 (lower right of Fig. 6) is dominated by the sulfate AOD reductions over the continents (except for in parts of Africa and other developing regions).

\subsubsection{Climate response}

The climate responses to the aerosol reductions in RCP8.5 are shown in Fig. 7 for the end of the century and in Figs. S9-S11 in the Supplement for the other three RCPs. As with Fig. 6, Fig. 7 shows the spatial pattern of the difference between the time-varying aerosol simulations and the fixed aerosol simulations (RCP8.5-RCP8.5_2005AER). Areas hatched with dots in each of the figures indicate statistically significant regions at the $95 \%$ confidence level according to Student's $t$ test. For temperature (upper left), the impact of aerosol reductions is almost entirely a warming effect, as expected, and nearly all of these increases are statistically significant. There are large areas of temperature increase in 2100 for East Asia, which is consistent with the largest decreases in AOD and aerosol emissions in this region. However, much of the strongest temperature increases driven by reduced aerosol emissions are located in or near the Arctic, suggesting that temperature change is non-local and does not necessarily occur in the areas where emissions are changing. Shindell et al. (2010) also have reported strong temperature increases in the Arctic where forcing was small in a global multimodel study.

Precipitation rate increases due to decreased aerosol emissions are largest over the tropical oceans, although increases are also observed over continents. In particular, some statistically significant precipitation rate increases occur over Europe, Russia, and Southeast Asia. Increases over North America are generally found to be statistically significant. However, much of the areas of increase over the oceans are statistically insignificant. Simulating precipitation, especially regional details, remains challenging for most models, including CM3 (Eden et al., 2012). In our results there are two intercontinental tropical convergence zones (ITCZ) near the equator, a common feature not only identified in CM3 but in other models as well (Lin, 2007). Both of the ITCZ show strong areas of precipitation enhancement despite not coinciding with aerosol decreases. The northward shift in the ITCZ is expected when removing a negative forcing in the Northern Hemisphere (i.e. aerosol decreases), but this does not appear to be statistically significant (Allen and Sherwood, 2011). Precipitation in the tropics is mainly a result of deep convection, and several studies have identified the effect of aerosols on deep convective circulation and precipitation (Bell et al., 2008; Lee, 2012; Rosenfeld et al., 2008). Using a cloud-system resolving model of a largescale deep convective system, Lee (2012) found that perturbations of aerosols in one domain can have teleconnections to other domains, acting to enhance precipitation in one domain while suppressing it in another through deep convection. Since the changes in precipitation are both positive and negative (mostly positive), and regions of precipitation increase that do coincide with aerosol decrease are few, it is 

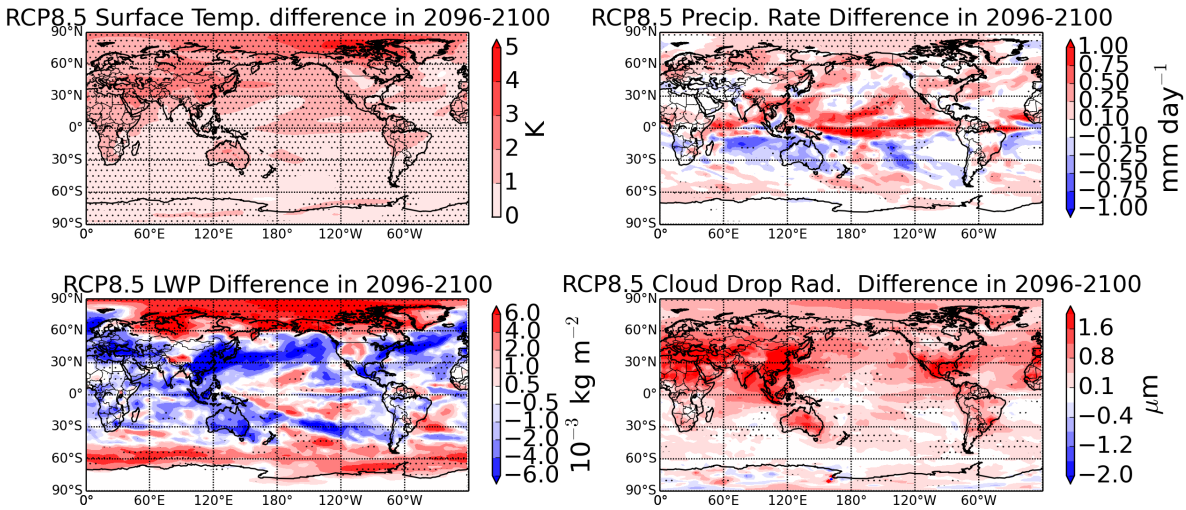

Figure 7. Changes in climate variables for a 5-year average over 2096-2100 for RCP8.5. Values represent differences between the projected RCP simulations and the fixed 2005 aerosol emissions case (RCP8.5-RCP8.5_2005AER). Hatched areas represent statistically significant changes at the $95 \%$ confidence level. Upper left: surface air temperature $(\mathrm{K})$, upper right: total precipitation rate $\left(\mathrm{mm} \mathrm{day}^{-1}\right)$, lower left: liquid water path $\left(\mathrm{kg} \mathrm{m}^{-2}\right)$, lower right: effective cloud droplet radius at cloud top $(\mu \mathrm{m})$.
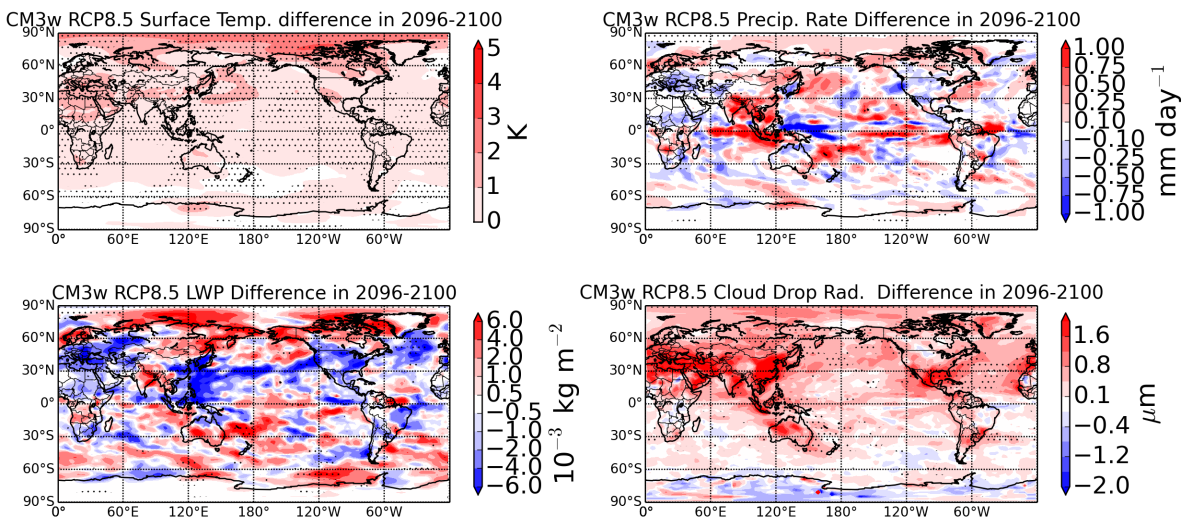

Figure 8. Same as Fig. 7, but for the case with reduced present-day effective aerosol radiative forcing (CM3w). Values represent differences between the projected RCP simulations and the fixed 2005 aerosol emissions case (CM3w_RCP8.5-CM3w_RCP8.5_2005AER).

likely that aerosols are affecting precipitation through other means than the aerosol indirect effect alone. The aerosols are also likely exerting an influence on atmospheric dynamics and weather patterns, causing large, non-uniform increases and decreases in the tropics. In particular, we postulate that the aerosol decreases in the continental domain are teleconnected to deep convection, resulting in both precipitation increases and decreases, as demonstrated by Lee (2012).

Liquid water path changes (Fig. 7, lower left panel) are largest over East Asia, which again is consistent with the simulated aerosol changes. Much of Europe and eastern North America also have large LWP decreases that coincide with aerosol emission decreases. However, there are large LWP increases in the Arctic region, most of which are statistically significant. These increases could be due to a feedback from the aerosol-driven temperature increase, as well as an increase in melting sea ice, making more water available for evaporation. Cloud droplet radius increases universally across the globe, with statistically significant changes occurring in the Northern Hemisphere, which is also where most of the aerosol reductions occur (Fig. 7, lower right). The co-location of the large increases in cloud droplet effective radius with large decreases in aerosol optical depth is a strong signal of the aerosol indirect effect, specifically the cloud albedo effect (we will explicitly show this in Sect. 5). Since the impacts of aerosol reductions on both liquid water path and cloud droplet effective radius are significant over the oceans in addition to the continents, we can also conclude that the aerosol reduction impacts are not necessary localized to their area of emission. Additionally, the increases of cloud droplet radius over the oceans may be amplified due to the greater susceptibility of clouds in clean environments compared to more polluted conditions.

Figure 8 shows the climate response in 2096-2100 for CM3w_RCP8.5. These responses are plotted on the same scale as Fig. 7 for comparison. For temperature, the pattern is quite similar, with the largest increases over the Arctic and the continents, and statistical significance nearly ev- 
erywhere. However, the magnitude of the temperature increases are noticeably smaller, owing to the reduced aerosol radiative forcing in the CM3w_RCP8.5 runs. Precipitation changes show a vastly different spatial pattern and slightly smaller magnitude in CM3w_RCP8.5 compared to RCP8.5 standard CM3, and overall it is slightly smaller in magnitude. However, much of this difference is due to the lack of a strong positive precipitation anomaly near the equator in CM3w_RCP8.5, which is not statistically significant in either set of simulations. Over the continents, the precipitation change is more qualitatively similar, for example over East and South Asia, where both sets of simulations show precipitation increases. CM3w_RCP8.5 produces a much larger precipitation increase over South Asia, perhaps due to the lower autoconversion threshold, although without statistical significance and only one ensemble member for CM3w, it is not possible to comment on the robustness of this result. Liquid water path decreases across eastern North America, Europe, and East Asia, consistent with areas where aerosol decreases are largest. Many of these decreases, however, lack statistical significance, and the magnitude of the change is much smaller than in standard CM3, as discussed previously. Cloud droplet effective radius changes are qualitatively similar, with large decreases over the continents. Compared to LWP, temperature, and precipitation, cloud droplet radius is least affected by the lowered autoconversion threshold (see also Fig. 9).

\subsubsection{Comparison of climate response driven by aerosol decreases and by all forcings}

Although the projected absolute climate response to decreasing aerosols is similar in all the RCP simulations, the magnitude of relative effects differs. By comparing our climate response to aerosol decreases (RCPx.x-RCPx.x_2005AER) to the climate response from all forcings (RCPx.X), we can roughly assess the relative importance of aerosol decreases to the total changes in climate for each RCP. The nonlinear nature of the global climate system means that these aerosol ratios are not directly additive with other ratios (say, GHGinduced climate changes) and are not the "true contributions" per se. However, comparing the magnitudes of the aerosolinduced climate changes to the total climate changes is a useful framing exercise. In instances where the all-forcing response sign differs from the aerosol-driven response, we use the absolute value (i.e. magnitude only) of the all-forcing response for the ratio calculation. We project from 2006 to the end-of-century a $0.97 \mathrm{~K}$ warming from aerosol emissions reductions in RCP2.6 (Fig. 5, Table 3) compared with a $1.5 \mathrm{~K}$ warming from all climate forcings together (Fig. 4), indicating that, under this scenario, two-thirds of the warming by 2100 would result from decreases in aerosol emissions. The RCP2.6 scenario indicates that even with aggressive reductions in the emissions of greenhouse gases, the projected reduction in aerosol emissions is likely to push the climate near
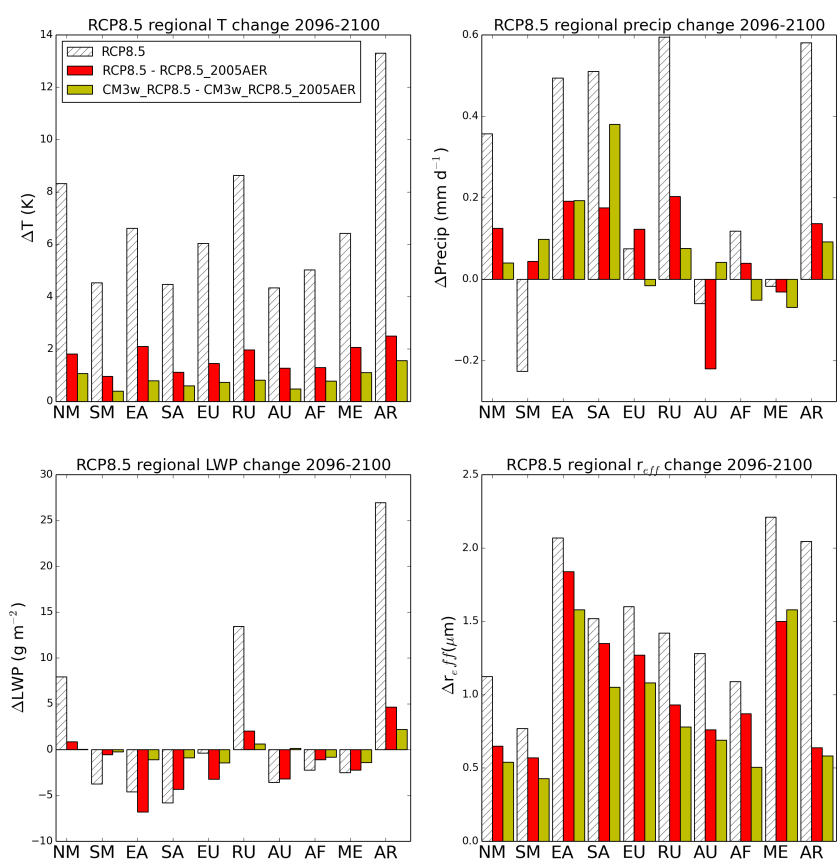

Figure 9. Regional comparison of climate response to aerosol decreases (RCP8.5-RCP8.5_2005AER, red bars), climate response to aerosol decreases under weaker aerosol forcing (CM3w_RCP8.5CM3w_RCP8.5_2005AER, yellow bars), and climate response to all-forcings (RCP8.5, white hatched bars) for a 5-year average over 2096-2100 for RCP8.5. Upper left: surface air temperature (K), upper right: total precipitation rate $\left(\mathrm{mm} \mathrm{day}^{-1}\right)$, lower left: liquid water path $\left(\mathrm{g} \mathrm{m}^{-2}\right)$, lower right: effective cloud droplet radius at cloud top $(\mu \mathrm{m})$. Regions are defined in Fig. 1.

the $2 \mathrm{~K}$ warming frequently cited as constituting "dangerous anthropogenic interference with the climate system" (Meinshausen et al., 2009). Since RCP2.6 projects the least warming from greenhouse gases, we find that this scenario is relatively the most susceptible (i.e. the largest percent effect) to unmasked aerosol warming as well as aerosol-driven changes in precipitation, LWP, and cloud droplet effective radius.

However, since GHG emissions over the past decade have been well above RCP2.6 and even slightly above RCP8.5 (Peters et al., 2012; Sanford et al., 2014), using RCP2.6 as a benchmark for the aerosol fraction of future climate change may be misleading. Figures 4 and 5 show that for RCP8.5, warming from aerosol reductions is roughly $1 \mathrm{~K}$ globally of a total warming of nearly $5 \mathrm{~K}$, or around $20 \%$. The RCP 8.5 precipitation increase of $0.09 \mathrm{~mm} \mathrm{day}^{-1}$ is about $36 \%$ of the all-forcing increase of $\sim 0.25 \mathrm{~mm} \mathrm{day}^{-1}$, while the globally averaged ratios for LWP and cloud droplet effective radius are 30 and $75 \%$, respectively. The large aerosol fraction for cloud droplet radius is expected, since cloud droplet size is highly dependent on existing aerosols, perhaps to a greater extent than the other three climate parameters presented here. Thus, even considering the high-emissions, lowmitigation RCP8.5 scenario, aerosol reductions are still a sur- 
prisingly important player in future global and regional climate change. However, an important caveat remains that our total present day aerosol effective radiative forcing is on the higher end of the IPCC range and thus may bias our results. We quantify this potential bias and discuss further below.

Figure 9 summarizes the 2096-2100 5-year average climate responses to decreasing aerosols (red bars, labeled RCP8.5-RCP8.5_2005AER) for each region and puts them in the context of the all-forcing (GHG and aerosols) results (white hatched bars, labeled RCP8.5). In the standard CM3 RCP runs, surface temperature increases due to aerosols are a substantial fraction of the all-forcing warming, even in RCP8.5 which features the largest warming from long-lived greenhouse gases. Much of East Asia, Australia, and the Middle East have ratios above $20 \%$ (seen in Fig. 9, comparing red bars with white hatched bars), indicating that the large aerosol decreases in these regions will contribute significantly to projected warming. The Arctic region (defined as everything above $66^{\circ} \mathrm{N}$ ) actually has the largest temperature increase due to decreasing aerosols, consistent with the polar amplification phenomenon. However, because climate warming from greenhouse gases is also amplified in the Arctic, the ratio of aerosol-induced warming to all-forcing warming is smaller than in many other regions. Even over the oceans (not shown), where anthropogenic aerosol abundances are low, we find their global decrease accounts for more than $10 \%$ of the all-forcing warming in these locations. Parts of East Asia and Europe, regions for which major aerosol decreases are expected, have high precipitation contributions approaching $40 \%$ (red and white bars the upper right panel of Fig. 9); however, this is not generalizable to all continental regions. Like precipitation, LWP contributions are small near the poles (see Arctic region), with sporadic regions of large LWP contributions in Asia, Australia, and the Middle East, indicating larger aerosol influence compared with allforcings in these regions. Finally, contributions of aerosol decreases to total cloud droplet radius changes approach 60 $90 \%$ for much of the globe between the latitudes $30^{\circ} \mathrm{S}$ and $60^{\circ} \mathrm{N}$. Ratios are particularly low in the Southern Ocean, where natural aerosols such as sea salt likely dominate CCN activation, and thus are less affected by decreasing anthropogenic aerosols.

Figure 9 also shows the comparison of aerosol decreasedriven climate response to all-forcing climate response for the CM3w_RCP8.5 runs with weaker present-day aerosol ERF (yellow bars in Fig. 9, labeled CM3w_RCP8.5CM3w_RCP8.5_2005AER). With some exceptions for precipitation in Asia, the climate responses to decreasing aerosols are always significantly less in CM3w_RCP8.5 than in the standard RCP8.5 runs. This is particularly noticeable in the temperature and LWP panels of Fig. 9. The temperature response in CM3w_RCP8.5 is sometimes half of the standard CM3 response, and the LWP is often an even smaller fraction. Thus, whereas RCP8.5 aerosol decreases may contribute up to $30-40 \%$ of the total warming in East Asia, this ratio is closer to $10 \%$ with the weakened aerosol forcing. While both versions of the model result in aerosol ERF within IPCC ranges, CM3w_RCP8.5 simulates a present-day ERF much closer to the center of the uncertainty range, suggesting that this estimate of aerosol decrease-driven climate response may be more robust.

\subsection{Regional climate response}

Using the regions defined in Fig. 1, we quantify changes in AOD, radiative forcing, and climate responses due to changes in aerosol concentrations on a regional scale in Tables 4 and 5 . We present the effective radiative forcing (or flux perturbation) as a difference between the 2096-2100 value and the 2000-2004 levels (as before), which is why these values are mostly positive. The AOD and climate differences are the difference between the time-varying $\mathrm{RCP}$ simulations and the 2005 fixed aerosol simulations (RCPx.xRCPx.x_2005AER) for the end of century (2096-2100 5year average). Values for RCP8.5 are shown in Table 4; RCP2.6 is shown in Table 5. These are chosen as the upper and lower ranges of AOD, radiative forcing, and climate response changes. Identical tables for RCP4.5 and RCP6 can be found in the Supplement (Tables S1 and S2). Table $\mathrm{S} 3$ shows the regional changes in climate response for CM3w_RCP8.5, although the AOD changes are not shown as we expect these to be minimal.

\subsubsection{East Asia}

Several of the largest aerosol-driven climate changes are found in the East Asian region. The region is defined to include all of China, Mongolia, Japan, and Korea (Fig. 1). East Asian emissions, AOD, radiative forcing, and climate response are analyzed below.

Figure $\mathrm{S} 12$ shows the anthropogenic $\mathrm{SO}_{2}, \mathrm{BC}$, and $\mathrm{OC}$ emissions time series from East Asia for the historical period and for each of the RCPs. For all species and all RCPs except RCP6, aerosol and aerosol precursor emissions are projected to peak in the 2010s. The trend for RCP6 for each species consists of a small increase in the 2010s, followed by a brief decrease and then a sharp increase with emissions peaking in 2050. This shifted trend results from the primary energy supply projections in RCP6, in which coal energy usage in East Asia increases steadily until peaking in 2050 2060. This reliance on coal as a primary fuel source results in a mid-century peak in not only aerosol and precursor emissions, but also $\mathrm{CO}_{2}$ emissions (Masui et al., 2011).

Figure S13 shows the East Asian region aerosol radiative forcing (calculated as a flux perturbation or effective radiative forcing) for all the RCPs and the historical period. This calculation is done by simply averaging over the region considering global aerosols as opposed to isolating the effect of East Asian aerosols alone. Radiative forcing from aerosols (direct + indirect) will continue to become more 
Table 4. Regional average changes in aerosol optical depth (AOD), effective radiative forcing (RF), temperature $(T)$, precipitation $(P)$, liquid water path (LWP), and cloud droplet effective radius $\left(R_{\text {eff }}\right)$ for RCP8.5 due to aerosol effects only at the end of the 21 st century. Values represent differences between RCP simulations and fixed 2005 simulations (RCP8.5-RCP8.5_2005AER. RF values represent the difference between 2100 and 2006 total aerosol forcing.

\begin{tabular}{lrrrrrrrr}
\hline & $\begin{array}{r}\mathrm{SO}_{4} \\
\mathrm{AOD}\end{array}$ & $\begin{array}{r}\mathrm{BC} \\
\mathrm{AOD}\end{array}$ & $\begin{array}{r}\mathrm{OC} \\
\mathrm{AOD}\end{array}$ & $\begin{array}{r}\mathrm{RF} \\
\left(\mathrm{W} \mathrm{m}^{-2}\right)\end{array}$ & $\begin{array}{r}T \\
(\mathrm{~K})\end{array}$ & $\begin{array}{r}P \\
\left(\mathrm{~mm} \mathrm{day}^{-1}\right)\end{array}$ & $\begin{array}{r}\text { LWP } \\
\left(\mathrm{g} \mathrm{m}^{-2}\right)\end{array}$ & $\begin{array}{r}R_{\text {eff }} \\
(\mu \mathrm{m})\end{array}$ \\
\hline $\mathrm{NM}$ & -0.13 & -0.0029 & -0.0039 & 1.53 & 1.81 & 0.125 & 0.852 & 0.649 \\
$\mathrm{SM}$ & -0.053 & -0.0053 & -0.030 & 0.89 & 0.96 & 0.044 & -0.553 & 0.571 \\
$\mathrm{EA}$ & -0.49 & -0.027 & -0.050 & 2.68 & 2.10 & 0.192 & -6.79 & 1.84 \\
$\mathrm{SA}$ & -0.41 & -0.020 & -0.102 & 3.85 & 1.11 & 0.175 & -4.34 & 1.35 \\
$\mathrm{EU}$ & -0.27 & -0.012 & -0.025 & 2.79 & 1.45 & 0.123 & -3.22 & 1.27 \\
$\mathrm{RU}$ & -0.14 & -0.0048 & -0.0085 & 1.80 & 1.97 & 0.203 & 2.04 & 0.93 \\
$\mathrm{AU}$ & -0.060 & -0.0012 & -0.0079 & 0.42 & 1.27 & -0.22 & -3.18 & 0.76 \\
$\mathrm{AF}$ & -0.12 & -0.0013 & -0.0105 & 0.90 & 1.29 & 0.039 & -1.11 & 0.87 \\
$\mathrm{ME}$ & -0.20 & -0.0034 & -0.0119 & 0.42 & 2.07 & -0.031 & -2.24 & 1.50 \\
\hline
\end{tabular}

Table 5. Same as Table 4, but for RCP2.6 and RCP2.6_2005AER.

\begin{tabular}{lrrrrrrrr}
\hline & $\begin{array}{r}\mathrm{SO}_{4} \\
\mathrm{AOD}\end{array}$ & $\begin{array}{r}\mathrm{BC} \\
\mathrm{AOD}\end{array}$ & $\begin{array}{r}\mathrm{OC} \\
\mathrm{AOD}\end{array}$ & $\begin{array}{r}\mathrm{RF} \\
\left(\mathrm{W} \mathrm{m}^{-2}\right)\end{array}$ & $\begin{array}{r}T \\
(\mathrm{~K})\end{array}$ & $\begin{array}{r}P \\
\left(\mathrm{~mm} \mathrm{day}^{-1}\right)\end{array}$ & $\begin{array}{r}\text { LWP } \\
\left(\mathrm{g} \mathrm{m}^{-2}\right)\end{array}$ & $\begin{array}{r}R_{\text {eff }} \\
(\mu \mathrm{m})\end{array}$ \\
\hline $\mathrm{NM}$ & -0.122 & -0.0029 & -0.0010 & 1.95 & 1.83 & 0.115 & -0.057 & 0.756 \\
$\mathrm{SM}$ & -0.068 & -0.0067 & -0.0275 & 1.16 & 0.95 & 0.0442 & -1.58 & 0.508 \\
$\mathrm{EA}$ & -0.43 & -0.033 & -0.061 & 3.06 & 1.71 & 0.33 & -3.25 & 1.85 \\
$\mathrm{SA}$ & -0.41 & -0.024 & -0.053 & 4.52 & 0.98 & 0.36 & -2.93 & 1.35 \\
$\mathrm{EU}$ & -0.269 & -0.013 & -0.017 & 3.20 & 1.65 & 0.087 & -2.66 & 1.24 \\
$\mathrm{RU}$ & -0.13 & -0.0059 & -0.0080 & 2.76 & 2.21 & 0.16 & 1.84 & 0.993 \\
$\mathrm{AU}$ & -0.045 & 0.0014 & 0.0023 & 0.63 & 0.73 & -0.107 & -1.05 & 0.543 \\
$\mathrm{AF}$ & -0.14 & -0.0075 & -0.070 & 0.97 & 1.16 & 0.016 & -0.69 & 1.06 \\
$\mathrm{ME}$ & -0.26 & -0.0072 & -0.016 & 0.67 & 1.75 & 0.039 & -1.36 & 2.40
\end{tabular}

negative (larger in magnitude) until about 2025, when it reaches nearly $-5 \mathrm{~W} \mathrm{~m}^{-2}$ over the region. For the rest of the century, the decrease in aerosol emissions (and AOD) results in a less negative radiative forcing (smaller in magnitude). Depending on the RCP, the aerosol forcing decreases in magnitude by about 2 to $3 \mathrm{~W} \mathrm{~m}^{-2}$ in 2100 . RCP6 has the weakest recovery over most of the century. This is likely due to the increase in reliance on coal power, allowing emissions to increase and peak over the first half of the 21 st century as mentioned above.

Climate response over East Asia is shown in Fig. 10 as differences between the time-varying RCP simulations and the fixed 2005 global aerosol emission simulations (RCPx.x-RCPx.x_2005AER). Temperature increases driven by aerosol emission changes are much larger than the global average, ranging from 1.1 to $2.2 \mathrm{~K}$ of warming in the standard CM3 run. This is consistent with the large decrease in aerosol optical depth ( -0.48 for sulfate, see Tables 4 and 5). In CM3w_RCP8.5, the temperature increase is smaller than all of the standard RCPs by the end of the century. The temperature, precipitation, and especially cloud droplet effective radius all respond differently to the unique energy supply trajectory of RCP6 than to the other RCPs. The warming around the middle of the century from aerosol emissions changes in RCP6 lags that in the other RCPs, and reaches only $1.1 \mathrm{~K}$ by 2100 (compared to $2.2 \mathrm{~K}$ for RCP8.5). Similar trends exist for precipitation rate and cloud droplet effective radius, which lag strongly around 2050, a time period in which the rest of the RCPs steadily increase. The annual trends in the indirect forcing related quantities, LWP and cloud droplet effective radius, again bear a striking similarity to the emissions trends (Fig. S12) on the regional scale as well as the global scale, as we previously showed.

\subsubsection{North America}

The climate responses over North America to global emission changes are shown in Fig. 11, and North American emissions and effective radiative forcing is shown in the Supplement Figs. S14 and S15. Unlike East Asia, anthropogenic emissions peak much earlier in North America. $\mathrm{SO}_{2}$ emissions reached a maximum in roughly 1970 and have been declining steadily since then, with each of the RCPs projecting the decline to continue in a similar manner. Total aerosol forcing follows a similar qualitative pattern as in East Asia; however, aerosol forcing over North America is projected 

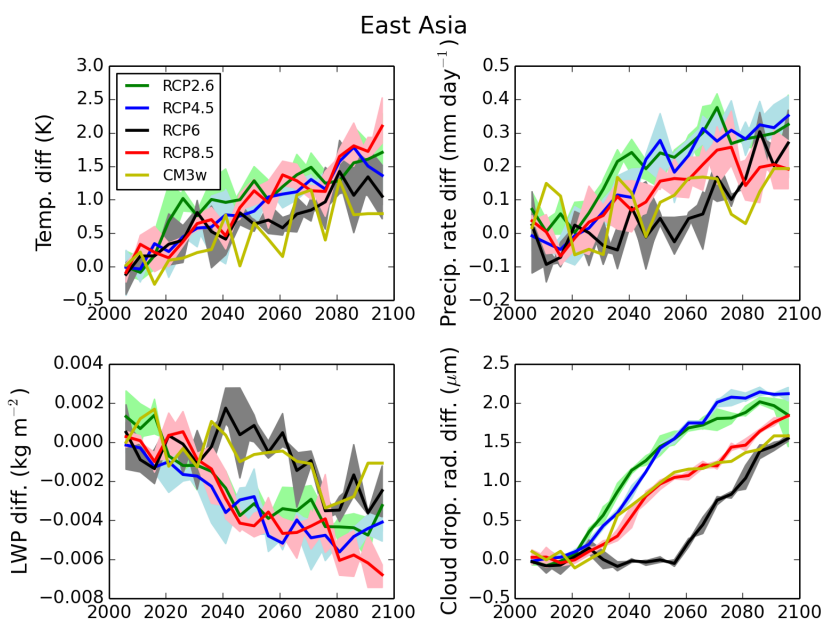

Figure 10. Trends in climate parameter differences from 20052100 for the East Asia Region. Values represent differences between the projected RCP simulations and the fixed 2005 aerosol emissions case (base case). Shaded light colors represent the range of the three ensemble members, solid lines are the ensemble means. Yellow lines represent the CM3w_RCP8.5 run.

to range from about 0 to $-0.5 \mathrm{~W} \mathrm{~m}^{-2}$ from 2006 to 2100 . Regionally averaged North American temperature increases by 1.5 to $2.0 \mathrm{~K}$ across each of the standard CM3 runs with the RCPs, and no particular RCP stands out from another at the end of the century, especially considering the ensemble member range. Again, temperature and precipitation response is much more muted in CM3w_RCP8.5. Precipitation increases by about $0.1 \mathrm{~mm}^{-1 a y}{ }^{-1}$ over North America due to declining aerosol emissions. There is almost no change in LWP over North America, and a slight increase is even projected in RCP8.5 by the end of the century, due to the warming effect on LWP over the extreme northern regions of North America. Despite having a major impact globally and in other regions, LWP changes are not noticeably different in CM3w_RCP8.5 compared to the standard CM3 runs. Cloud droplet radius increases nearly identically across the RCPs for the entire century, except for RCP2.6, which stands out as having the greatest effective radius increase for the first two-thirds of the 21st century. North American RCP2.6 SO emissions (Fig. S14) and AOD (not shown) decrease substantially over the first half and level off for the remainder of the 21 st century, which explains the trend in cloud droplet radius.

\section{Implications and discussion}

\subsection{Comparison to previous studies}

Our estimated range $\left(1.05-1.37 \mathrm{~W} \mathrm{~m}^{-2}\right)$ for the effective radiative forcing change resulting from projected future aerosol and precursor emission reductions falls within the range estimated in previous literature, as shown in Table 1. In partic-
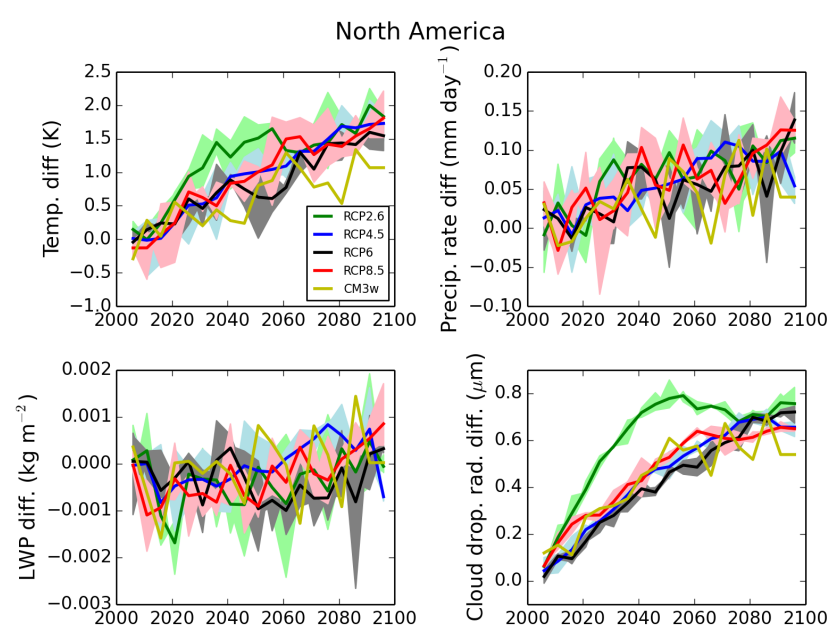

Figure 11. Trends in climate parameter differences from 20052100 for the North America region. Values represent differences between the projected RCP simulations and the fixed 2005 aerosol emissions case (base case). Shaded light colors represent the range of the three ensemble members, solid lines are the ensemble means. Yellow lines represent the CM3w_RCP8.5 run.

ular, Shindell et al. (2013) estimates a present-day to end-ofcentury aerosol forcing change of $0.68-1.42 \mathrm{~W} \mathrm{~m}^{-2}$. When considering our CM3w_RCP8.5 simulations with lower present-day aerosol ERF, our lower estimate of $1.05 \mathrm{~W} \mathrm{~m}^{-2}$ is actually much closer and in better agreement with the values in Shindell et al. (2013). Our global temperature increases from aerosol decreases across the RCPs of 0.72 $1.04 \mathrm{~K}$ compares well with many previous studies (see Table 1), which have also found that temperatures will increase as much as $1 \mathrm{~K}$ due to aerosol decreases. Our global precipitation results also compare well with previous modeling studies. For instance, both Levy et al. (2013) and Rotstayn et al. (2013) found global increases in 2100 of $0.1 \mathrm{~mm} \mathrm{day}^{-1}$, similar to the top of our projected range of $0.078-0.093 \mathrm{~mm} \mathrm{day}^{-1}$. The effect of future aerosol decreases on liquid water path and cloud droplet effective radius were not considered by most of the previous literature, with the exception of Takemura (2012), who reports a change in LWP of around $3 \mathrm{~g} \mathrm{~m}^{-2}$, significantly higher than the 0.5 $1.0 \mathrm{~g} \mathrm{~m}^{-2}$ reported here. However, cloud droplet radius values compare much better. The aerosol-driven increases are very similar to those reported by Takemura (2012), who reported a difference in effective radius of about $0.6 \mu \mathrm{m}$ at the tropopause from 2000 to 2100 ., compared to $0.5-0.6 \mu \mathrm{m}$ in our study. However, Takemura (2012) did not conduct fixed aerosol simulations (RCPx.x_2005AER) and thus did not include the effect of climate change on future aerosol concentrations. 

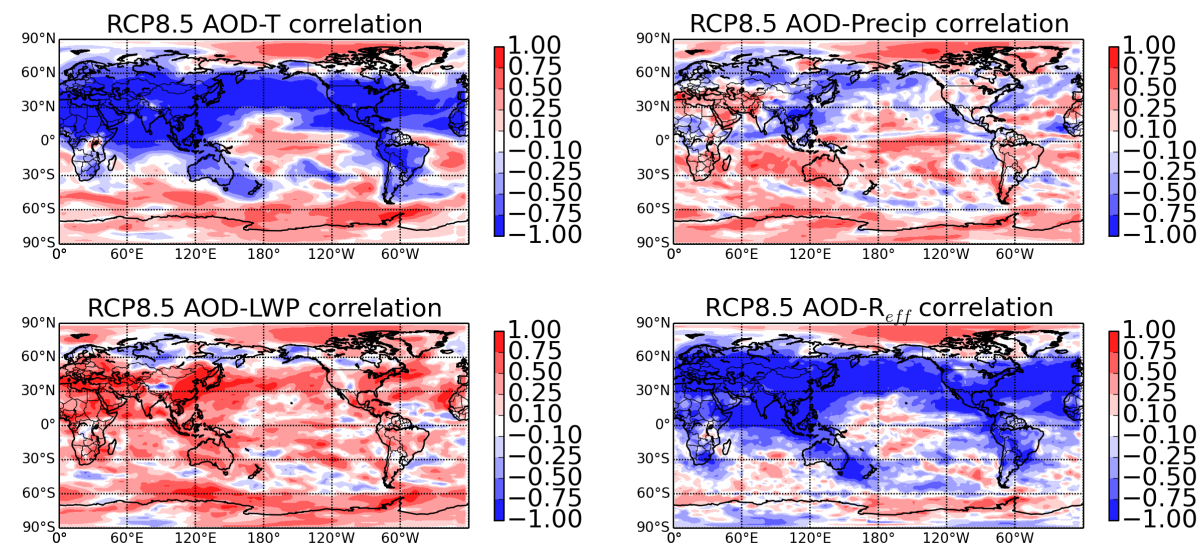

Figure 12. Correlations of aerosol-driven changes in temperature $(T)$, precipitation rate (Precip), liquid water path (LWP), and cloud droplet radius $\left(R_{\text {eff }}\right)$ with total anthropogenic aerosol optical depth (sulfate, black carbon, and organic carbon AOD) for RCP8.5.

\subsection{Correlations between aerosols and climate response}

It remains difficult to attribute specific changes in climate parameters to changes in aerosol emissions or optical depth, due to the complexity of global coupled chemistry-climate models and the complexity of the climate system as a whole. In Fig. 12 we plot spatial correlations between RCP8.5 emission-driven changes in aerosol optical depth values and four climate parameters as an attempt to relate an aerosol quantity with corresponding climate response endpoints. Correlation plots for the three other RCPs are in the Supplement (Figs. S16-S18). We also plot $\Delta \mathrm{C} / \triangle \mathrm{AOD}$ for RCP8.5 in Fig. S19, where $\Delta \mathrm{C}$ represents the change from the beginning to end of the 21st century for a given climate response variable, and $\triangle \mathrm{AOD}$ for the change in AOD. For RCP8.5 AOD-temperature correlation, there is a strong relationship $(r<-0.75)$ over virtually all of the continental areas and the northern Atlantic and Pacific oceans, which is expected due to aerosols having a net cooling influence on climate via the direct and indirect effects. The weak correlations over the tropical Pacific correspond to AOD increases and less extreme temperature increases over these regions, whereas the Southern Ocean positive correlations are caused by increases in temperature and very small increases (due to DMS emissions increases) in sulfate AOD (supported by the weak correlation values). AOD increases are also projected in parts of the Arctic, some of which may be related to the Arctic haze phenomenon. Coupled with strong temperature increases in the Arctic, positive AOD-temperature correlations are projected.

Precipitation is shown in the upper-right and is correlated both positively and negatively with changes AOD (Fig. 12). Over East Asia and parts of Europe, AOD and precipitation are somewhat strongly anti-correlated $(r<-0.5)$, which is expected according to the aerosol indirect effect on clouds. However, the mixed representation between positively and negatively correlated regions, as well as the overall weak correlations, suggests that it is not the aerosol indirect effect alone that is the mechanism for the projected effect of aerosols on precipitation. Instead, this is likely a signal of aerosol impacts on circulation, dynamics, and weather patterns, which can have feedback effects on precipitation. As described in Sect. 4.1.2, we believe that aerosol perturbations over the continents may have teleconnections to precipitation enhancements in deep-convective cloud systems, accounting for the positive correlation over the tropics. In Fig. S20 we also correlate AOD perturbations with deep convective precipitation and find generally stronger negative correlations $(r \sim-0.75)$ over much of the Northern Hemisphere but roughly the same positive correlations over much of the oceans, including the tropics.

Liquid water path (LWP) is correlated positively $(r>0.5)$ with AOD over nearly the entire globe, with notable exceptions in Alaska and northern Russia. Additionally, areas with the strongest change in AOD seem to have the strongest LWP changes as well, possibly implicating the aerosol indirect effect as the mechanism behind the correlation. Similarly, cloud droplet radius is very strongly anti-correlated almost throughout the entire globe $(r>0.75)$, with the exception of the Arctic, which is also affected by the aerosol-driven increase in temperature.

\subsection{Similarity among the RCPs}

Our results are of course dependent on the GFDL CM3 model as well as the emissions projections provided by each of the RCPs, which have limitations. First, since recent GHG emissions are tracking at or above RCP8.5 (Peters et al., 2012; Sanford et al., 2014), the high emissions case, the RCPs may be optimistic in their greenhouse gas emissions projections. Second, the individual RCP pathways are often very similar to one another on both the global and regional scales, especially for air pollutant emissions and related quantities (see Fig. 2). This leads to a limited spread 
in the possible climate responses which likely does not explore the breadth of possible technology and policy driven changes in future aerosol emissions. For example, the spread in precipitation rate response driven by decreased aerosol emissions across scenarios is only $0.015 \mathrm{~mm} \mathrm{day}^{-1}$. In almost every example, the trends of AOD, radiative forcing, and climate response in each of the RCPs does not substantially differ (Table 3, Fig. 5). An exception to this is with the CM3w_RCP8.5 runs, which does produce a significantly different and more unique climate response to decreasing aerosols in the 21 st century. Despite vastly different energy supply scenarios and climate policies, it appears to be of little consequence which RCP is used to determine the impact of the declining aerosol emissions on climate in the standard CM3 runs. Regardless of the level of projected GHG emissions in the future, decreasing aerosol concentrations will likely result in substantially warmer temperatures (see Tables 3-5) and regionally varied changes in precipitation and other climate parameters. Finally, unlike the IPCC SRES inventories, the RCPs do not begin from narrative storylines of what energy, population, and economic conditions will be like in the future making it difficult to link an RCP with a particular development pathway. However, recent work has attempted to map IPCC SRES illustrative storylines onto each of the RCPs (van Vuuren and Carter, 2013).

\section{Conclusions}

We present a global climate modeling study of the impact of the projected future decrease of aerosol emissions using the GFDL Climate Model 3 (CM3). Future emissions follow the Representative Concentration Pathway (RCP) projections, which consist of four emissions trajectories that are consistent with global average radiative forcing values in 2100 of approximately $2.6,4.5,6.0$, and $8.5 \mathrm{~W} \mathrm{~m}^{-2}$, respectively. In response to the continuing human health cost of air pollution, each of the RCP scenarios projects that global emissions of aerosols and their precursors will decline as the result of policy decisions to improve air quality. However, aerosols also have a net cooling effect on climate that will be reduced (i.e., warming) as the emissions decline. Aerosols also impact clouds and precipitation, the effects of which will also change under the projected diminishing emissions. We implement the RCP emissions inventories into CM3 and run two sets of simulations for each of the pathways: one in which aerosol and aerosol precursor emissions are allowed to vary as projected by the RCPs, and another in which they are fixed at 2005 levels. The sets of fixed emissions simulations serve as controls to analyze the changes in AOD, radiative forcing, and climate solely due to the projected emission reductions of aerosols and their precursors.

Changes in aerosol optical depth closely follow the emissions changes spatially and temporally. Regionally, there are large AOD decreases over the continents, especially in East and South Asia. A few localities exhibit increases in aerosol optical depth, in some cases this is due to natural sources of aerosol or feedbacks on precipitation and wet deposition. In other cases, the AOD increases are indicative of local emissions increases, which are expected to occur in parts of Central Africa and Indonesia.

The projected decreases in aerosol emissions and optical depth lead to a decrease in the magnitude of the aerosol direct and indirect radiative forcing. CM3 predicts an aerosol direct plus indirect radiative forcing of $-1.8 \mathrm{~W} \mathrm{~m}^{-2}$ from the pre-industrial period to present day, which is close to the upper range of $-1.9 \mathrm{~W} \mathrm{~m}^{-2}$ used by the IPCC (Myhre et al., 2013). To test robustness of our results to the strength of aerosol forcing, we run additional simulations in which the autoconversion threshold is lowered, resulting in a presentday aerosol ERF of about $-1.0 \mathrm{~W} \mathrm{~m}^{-2}$. By 2100 , the aerosol forcing is projected to diminish to between $-0.21 \mathrm{~W} \mathrm{~m}^{-2}$ in RCP2.6 and $-0.53 \mathrm{~W} \mathrm{~m}^{-2}$ in RCP8.5. Our results therefore indicate that a large positive forcing, up to $1 \mathrm{~W} \mathrm{~m}^{-2}$ or greater, will result from the projected decrease in aerosol and aerosol precursor emissions. This forcing has a strong impact on climate, warming temperatures by as much as $1 \mathrm{~K}$ globally and up to $2-3 \mathrm{~K}$ regionally in the standard CM3 $\mathrm{RCP}$ runs, with a much more modest response in the reduced aerosol forcing runs of $0.5 \mathrm{~K}$ globally. Aerosol reductiondriven surface temperature response generally accounts for a large fraction of the total all-forcing response. Ratios over East Asia can exceed $30 \%$ in RCP8.5, and are even higher in the other scenarios that do not feature as much greenhouse gas-induced climate warming. However, these ratios are closer to $10-20 \%$ in most regions and globally when we consider the reduced aerosol forcing RCP8.5 run. Global precipitation rates are projected to increase by as much as $3 \%$ of 2005 values or $0.1 \mathrm{~mm} \mathrm{day}^{-1}$, with greater regional impacts. Inconsistent with Levy et al. (2013), we found significant local precipitation changes co-located with areas of large aerosol decrease (e.g., East Asia). On the global scale, aerosol reduction-driven changes in AOD and climate response trajectories do not vary significantly among the four RCPs, especially towards the end of the century, despite stemming from nominally different scenarios. Mid-century variation in the climate response and radiative forcing trajectories closely follows the aerosol and precursor emissions trajectories (and thus the energy use trajectories), even for climate parameters such as liquid water path and cloud droplet effective radius.

Temperature, liquid water path, and cloud droplet effective radius are strongly correlated spatially with aerosol optical depth changes (as would be expected from their parameterizations), confirming the localized effect that aerosols have on climate forcing. Precipitation and AOD changes were only weakly correlated, with even the sign of the correlation varying spatially. This suggests that local changes in aerosol quantity are not strongly tied to local precipitation events, but that large-scale changes in atmospheric circulation in- 
stead play a role in the effect of aerosols on precipitation. Future work is needed to identify the mechanisms behind the precipitation response to inhomogeneous changes in aerosol concentrations.

Our results indicate the need for a tighter coupling among climate and air pollution control policies, in order to avoid unintended warming from air pollution reductions. To simultaneously clean the air and avoid exacerbating global warming, more aggressive greenhouse gas mitigation will be necessary to compensate for the unintended aerosol-driven warming. Future work on reductions of specific emissions sources (e.g., activities with large emissions of BC) that have positive impacts on both human health and climate will be beneficial. Additional work is also needed to understand the connection between changes in aerosol quantities and corresponding climate responses. Future scenario development that better replicates explicit policy and technology changes driving emission reductions of air pollutants will provide scenarios that have larger variations among them, which will allow a more thorough analysis of the impacts of various mitigation efforts. Finally, the impact of nitrate aerosols on future climate needs to be explored. Many current studies have omitted nitrate, but the combination of increasing ammonia emissions and decreasing sulfate in the future will likely promote nitrate formation. If nitrate does increase in significance, society might simply replace the lost sulfate forcing and human health impact with a similar impact from nitrate aerosol.

\section{The Supplement related to this article is available online at doi:10.5194/acp-15-12681-2015-supplement.}

Acknowledgements. D. Westervelt was supported by a fellowship from the Science, Technology and Environmental Policy (STEP) program at the Woodrow Wilson School of Public and International Affairs at Princeton University.

Edited by: K. Tsigaridis

\section{References}

Ackerman, A. S., Kirkpatrick, M. P., Stevens, D. E., and Toon, O. B.: The impact of humidity above stratiform clouds on indirect aerosol climate forcing, Nature, 432, 1014-1017, doi:10.1038/nature03174, 2004.

Albrecht, B. A.: Aerosols, Cloud Microphysics, and Fractional Cloudiness, Science, 245, 1227-1230, doi:10.1126/science.245.4923.1227, 1989.

Allen, R. J. and Sherwood, S. C.: The impact of natural versus anthropogenic aerosols on atmospheric circulation in the Community Atmosphere Model, Clim. Dynam., 36, 1959-1978, doi:10.1007/s00382-010-0898-8, 2010.
Arneth, A., Unger, N., Kulmala, M., and Andreae, M. O.: Atmospheric science. Clean the air, heat the planet?, Science, 326, 672-673, doi:10.1126/science.1181568, 2009.

Bauer, S. E., Koch, D., Unger, N., Metzger, S. M., Shindell, D. T., and Streets, D. G.: Nitrate aerosols today and in 2030: a global simulation including aerosols and tropospheric ozone, Atmos. Chem. Phys., 7, 5043-5059, doi:10.5194/acp-7-5043-2007, 2007.

Bell, T. L., Rosenfeld, D., Kim, K.-M., Yoo, J.-M., Lee, M.-I., and Hahnenberger, M.: Midweek increase in U.S. summer rain and storm heights suggests air pollution invigorates rainstorms, J. Geophys. Res., 113, D02209, doi:10.1029/2007JD008623, 2008.

Bellouin, N., Rae, J., Jones, A., Johnson, C., Haywood, J., and Boucher, O.: Aerosol forcing in the Climate Model Intercomparison Project (CMIP5) simulations by HadGEM2-ES and the role of ammonium nitrate, J. Geophys. Res., 116, D20206, doi:10.1029/2011JD016074, 2011.

Bond, T. C., Doherty, S. J., Fahey, D. W., Forster, P. M., Berntsen, T., DeAngelo, B. J., Flanner, M. G., Ghan, S., Kärcher, B., Koch, D., Kinne, S., Kondo, Y., Quinn, P. K., Sarofim, M. C., Schultz, M. G., Schulz, M., Venkataraman, C., Zhang, H., Zhang, S., Bellouin, N., Guttikunda, S. K., Hopke, P. K., Jacobson, M. Z., Kaiser, J. W., Klimont, Z., Lohmann, U., Schwarz, J. P., Shindell, D., Storelvmo, T., Warren, S. G., and Zender, C. S.: Bounding the role of black carbon in the climate system: A scientific assessment, J. Geophys. Res.-Atmos., 118, 5380-5552, doi:10.1002/jgrd.50171, 2013.

Chalmers, N., Highwood, E. J., Hawkins, E., Sutton, R., and Wilcox, L. J.: Aerosol contribution to the rapid warming of nearterm climate under RCP 2.6, Geophys. Res. Lett., 39, L18709, doi:10.1029/2012GL052848, 2012.

Chen, W.-T., Lee, Y. H., Adams, P. J., Nenes, A., and Seinfeld, J. H.: Will black carbon mitigation dampen aerosol indirect forcing?, Geophys. Res. Lett., 37, L09801, doi:10.1029/2010GL042886, 2010.

Dawson, J. P., Adams, P. J., and Pandis, S. N.: Sensitivity of $\mathrm{PM}_{2.5}$ to climate in the Eastern US: a modeling case study, Atmos. Chem. Phys., 7, 4295-4309, doi:10.5194/acp-7-4295-2007, 2007.

Dentener, F., Kinne, S., Bond, T., Boucher, O., Cofala, J., Generoso, S., Ginoux, P., Gong, S., Hoelzemann, J. J., Ito, A., Marelli, L., Penner, J. E., Putaud, J.-P., Textor, C., Schulz, M., van der Werf, G. R., and Wilson, J.: Emissions of primary aerosol and precursor gases in the years 2000 and 1750 prescribed data-sets for AeroCom, Atmos. Chem. Phys., 6, 4321-4344, doi:10.5194/acp-64321-2006, 2006.

Donner, L. J., Wyman, B. L., Hemler, R. S., Horowitz, L. W., Ming, Y., Zhao, M., Golaz, J.-C., Ginoux, P., Lin, S.-J., Schwarzkopf, M. D., Austin, J., Alaka, G., Cooke, W. F., Delworth, T. L., Freidenreich, S. M., Gordon, C. T., Griffies, S. M., Held, I. M., Hurlin, W. J., Klein, S. A., Knutson, T. R., Langenhorst, A. R., Lee, H.-C., Lin, Y., Magi, B. I., Malyshev, S. L., Milly, P. C. D., Naik, V., Nath, M. J., Pincus, R., Ploshay, J. J., Ramaswamy, V., Seman, C. J., Shevliakova, E., Sirutis, J. J., Stern, W. F., Stouffer, R. J., Wilson, R. J., Winton, M., Wittenberg, A. T., and Zeng, F.: The Dynamical Core, Physical Parameterizations, and Basic Simulation Characteristics of the Atmospheric Component AM3 of the GFDL Global Coupled Model CM3, J. Climate, 24, 34843519, doi:10.1175/2011JCLI3955.1, 2011. 
Eden, J. M., Widmann, M., Grawe, D., and Rast, S.: Skill, Correction, and Downscaling of GCM-Simulated Precipitation, J. Climate, 25, 3970-3984, doi:10.1175/JCLI-D-11-00254.1, 2012.

Fang, Y., Fiore, A. M., Horowitz, L. W., Gnanadesikan, A., Held, I., Chen, G., Vecchi, G., and Levy, H.: The impacts of changing transport and precipitation on pollutant distributions in a future climate, J. Geophiys. Res.-Atmos., 116, 1-14, doi:10.1029/2011JD015642, 2011.

Gillett, N. P. and von Salzen, K.: The role of reduced aerosol precursor emissions in driving near-term warming, Environ. Res. Lett., 8, 034008, doi:10.1088/1748-9326/8/3/034008, 2013.

Golaz, J.-C., Salzmann, M., Donner, L. J., Horowitz, L. W., Ming, Y., and Zhao, M.: Sensitivity of the Aerosol Indirect Effect to Subgrid Variability in the Cloud Parameterization of the GFDL Atmosphere General Circulation Model AM3, J. Climate, 24, 3145-3160, doi:10.1175/2010JCLI3945.1, 2011.

Golaz, J.-C., Horowitz, L. W., and Levy, H.: Cloud tuning in a coupled climate model: Impact on 20th century warming, Geophys. Res. Lett., 40, 2246-2251, doi:10.1002/grl.50232, 2013.

Griffies, S. M., Winton, M., Donner, L. J., Horowitz, L. W. Downes, S. M., Farneti, R., Gnanadesikan, A., Hurlin, W. J., Lee, H., Liang, Z., Palter, J. B., Samuels, B. L., Wittenberg, A. T., Wyman, B., Yin, J., and Zadeh, N.: The GFDL CM3 Coupled Climate Model: Characteristics of the Ocean and Sea Ice Simulations, J. Climate, 24, 3520-3544, doi:10.1175/2011JCLI3964.1, 2011.

Guo, H., Golaz, J.-C., Donner, L. J., Ginoux, P., and Hemler, R. S.: Multivariate Probability Density Functions with Dynamics in the GFDL Atmospheric General Circulation Model: Global Tests, J. Climate, 27, 2087-2108, doi:10.1175/JCLI-D-13-00347.1, 2014.

Hauglustaine, D. A., Balkanski, Y., and Schulz, M.: A global model simulation of present and future nitrate aerosols and their direct radiative forcing of climate, Atmos. Chem. Phys., 14, 1103111063, doi:10.5194/acp-14-11031-2014, 2014.

Heald, C. L., Henze, D. K., Horowitz, L. W., Feddema, J., Lamarque, J.-F., Guenther, A., Hess, P. G., Vitt, F., Seinfeld, J. H., Goldstein, A. H., and Fung, I.: Predicted change in global secondary organic aerosol concentrations in response to future climate, emissions, and land use change, J. Geophys. Res.-Atmos., 113, D05211, doi:10.1029/2007JD009092, 2008.

Horowitz, L. W.: Past, present, and future concentrations of tropospheric ozone and aerosols: Methodology, ozone evaluation, and sensitivity to aerosol wet removal, J. Geophys. Res., 111, D22211, doi:10.1029/2005JD006937, 2006.

Horowitz, L. W., Walters, S., Mauzerall, D. L., Emmons, L. K., Rasch, P. J., Granier, C., Tie, X., Lamarque, J.-F., Schultz, M. G., Tyndall, G. S., Orlando, J. J., and Brasseur, G. P.: A global simulation of tropospheric ozone and related tracers: Description and evaluation of MOZART, version 2, J. Geophys. Res.-Atmos., 108, 4784, doi:10.1029/2002JD002853, 2003.

Jacob, D. J. and Winner, D. A.: Effect of climate change on air quality, Atmos. Environ., 43, 51-63, doi:10.1016/j.atmosenv.2008.09.051, 2009.

Kato, E., Kawamiya, M., Kinoshita, T., and Ito, A.: Development of spatially explicit emission scenario from land-use change and biomass burning for the input data of climate projection, Procedia Environ. Sci., 6, 146-152, doi:10.1016/j.proenv.2011.05.015, 2011.
Khairoutdinov, M. and Kogan, Y.: A New Cloud Physics Parameterization in a Large-Eddy Simulation Model of Marine Stratocumulus, Mon. Weather Rev., 128, 229-243, doi:10.1175/15200493(2000)128<0229:ANCPPI>2.0.CO;2, 2000.

King, M. D., Menzel, W. P., Kaufman, Y. J., Tanré, D., Gao, B., Platnick, S., Ackerman, S. A., Remer, L. A., Pincus, R., and Hubanks, P. A.: Cloud and Aerosol Properties, Precipitable Water, and Profiles of Temperature and Water Vapor from MODIS, IEEE Trans. Geosci. Remote Sens., 41, 442-458, 2003.

Klimont, Z., Smith, S. J., and Cofala, J.: The last decade of global anthropogenic sulfur dioxide: 2000-2011 emissions, Environ. Res. Lett., 8, 014003, doi:10.1088/1748-9326/8/1/014003, 2013.

Kloster, S., Dentener, F., Feichter, J., Raes, F., Lohmann, U., Roeckner, E., and Fischer-Bruns, I.: A GCM study of future climate response to aerosol pollution reductions, Clim. Dynam., 34, 11771194, doi:10.1007/s00382-009-0573-0, 2009.

Kopp, R. E. and Mauzerall, D. L.: Assessing the climatic benefits of black carbon mitigation, P. Natl. Acad. Sci. USA, 107, 1170311708, doi:10.1073/pnas.0909605107, 2010.

Lamarque, J.-F., Bond, T. C., Eyring, V., Granier, C., Heil, A., Klimont, Z., Lee, D., Liousse, C., Mieville, A., Owen, B., Schultz, M. G., Shindell, D., Smith, S. J., Stehfest, E., Van Aardenne, J., Cooper, O. R., Kainuma, M., Mahowald, N., McConnell, J. R., Naik, V., Riahi, K., and van Vuuren, D. P.: Historical (1850-2000) gridded anthropogenic and biomass burning emissions of reactive gases and aerosols: methodology and application, Atmos. Chem. Phys., 10, 7017-7039, doi:10.5194/acp10-7017-2010, 2010.

Lamarque, J.-F., Kyle, G. P., Meinshausen, M., Riahi, K., Smith, S. J., Vuuren, D. P., Conley, A. J., and Vitt, F.: Global and regional evolution of short-lived radiatively-active gases and aerosols in the Representative Concentration Pathways, Climatic Change, 109, 191-212, doi:10.1007/s10584-011-0155-0, 2011.

Lee, S. S.: Effect of Aerosol on Circulations and Precipitation in Deep Convective Clouds, J. Atmos. Sci., 69, 1957-1974, doi:10.1175/JAS-D-11-0111.1, 2012.

Leibensperger, E. M., Mickley, L. J., Jacob, D. J., Chen, W.-T., Seinfeld, J. H., Nenes, A., Adams, P. J., Streets, D. G., Kumar, N., and Rind, D.: Climatic effects of 1950-2050 changes in US anthropogenic aerosols - Part 1: Aerosol trends and radiative forcing, Atmos. Chem. Phys., 12, 3333-3348, doi:10.5194/acp-12-33332012, 2012a.

Leibensperger, E. M., Mickley, L. J., Jacob, D. J., Chen, W.-T., Seinfeld, J. H., Nenes, A., Adams, P. J., Streets, D. G., Kumar, N., and Rind, D.: Climatic effects of 1950-2050 changes in US anthropogenic aerosols - Part 2: Climate response, Atmos. Chem. Phys., 12, 3349-3362, doi:10.5194/acp-12-3349-2012, 2012 b.

Levy, H., Horowitz, L. W., Schwarzkopf, M. D., Ming, Y., Golaz, J.-C., Naik, V., and Ramaswamy, V.: The roles of aerosol direct and indirect effects in past and future climate change, J. Geophys. Res.-Atmos., 118, 4521-4532, doi:10.1002/jgrd.50192, 2013.

Lin, J.-L.: The Double-ITCZ Problem in IPCC AR4 Coupled GCMs: Ocean-Atmosphere Feedback Analysis, J. Climate, 20, 4497-4525, doi:10.1175/JCLI4272.1, 2007.

Lin, S. J. and Rood, R. B.: Multidimensional flux-form semiLagrangian transport schemes, Mon. Weather Rev., 124, 20462070, 1996.

Liousse, C., Assamoi, E., Criqui, P., Granier, C., and Rosset, R.: Explosive growth in African combustion emissions from 
2005 to 2030, Environ. Res. Lett., 9, 035003, doi:10.1088/17489326/9/3/035003, 2014.

Lohmann, U. and Feichter, J.: Global indirect aerosol effects: a review, Atmos. Chem. Phys., 5, 715-737, doi:10.5194/acp-5-7152005, 2005.

Lohmann, U., Rotstayn, L., Storelvmo, T., Jones, A., Menon, S., Quaas, J., Ekman, A. M. L., Koch, D., and Ruedy, R.: Total aerosol effect: radiative forcing or radiative flux perturbation?, Atmos. Chem. Phys., 10, 3235-3246, doi:10.5194/acp-10-32352010, 2010.

Makkonen, R., Asmi, A., Kerminen, V.-M., Boy, M., Arneth, A., Hari, P., and Kulmala, M.: Air pollution control and decreasing new particle formation lead to strong climate warming, Atmos. Chem. Phys., 12, 1515-1524, doi:10.5194/acp-12-15152012, 2012.

Masui, T., Matsumoto, K., Hijioka, Y., Kinoshita, T., Nozawa, T., Ishiwatari, S., Kato, E., Shukla, P. R., Yamagata, Y., and Kainuma, M.: An emission pathway for stabilization at $6 \mathrm{Wm}-2$ radiative forcing, Climatic Change, 109, 59-76, doi:10.1007/s10584-011-0150-5, 2011.

Meinshausen, M., Meinshausen, N., Hare, W., Raper, S. C. B., Frieler, K., Knutti, R., Frame, D. J., and Allen, M. R.: Greenhouse-gas emission targets for limiting global warming to 2 degrees C, Nature, 458, 1158-62, doi:10.1038/nature08017, 2009.

Meinshausen, M., Smith, S. J., Calvin, K., Daniel, J. S., Kainuma, M. L. T., Lamarque, J.-F., Matsumoto, K., Montzka, S. A., Raper, S. C. B., Riahi, K., Thomson, A., Velders, G. J. M., and Vuuren, D. P. P.: The RCP greenhouse gas concentrations and their extensions from 1765 to 2300, Climatic Change, 109, 213-241, doi:10.1007/s10584-011-0156-z, 2011.

Menon, S., Unger, N., Koch, D., Francis, J., Garrett, T., Sednev, I., Shindell, D., and Streets, D.: Aerosol climate effects and air quality impacts from 1980 to 2030, Environ. Res. Lett., 3, 024004, doi:10.1088/1748-9326/3/2/024004, 2008.

Ming, Y. and Ramaswamy, V.: Nonlinear Climate and Hydrological Responses to Aerosol Effects, J. Climate, 22, 1329-1339, doi:10.1175/2008JCLI2362.1, 2009.

Ming, Y. and Ramaswamy, V.: A Model Investigation of AerosolInduced Changes in Tropical Circulation, J. Climate, 24, 51255133, doi:10.1175/2011JCLI4108.1, 2011.

Ming, Y., Ramaswamy, V., Donner, L. J., and Phillips, V. T. J.: A New Parameterization of Cloud Droplet Activation Applicable to General Circulation Models, J. Atmos. Sci., 63, 1348-1356, doi:10.1175/JAS3686.1, 2006.

Ming, Y., Ramaswamy, V., Donner, L. J., Phillips, V. T. J., Klein, S. A., Ginoux, P. A., and Horowitz, L. W.: Modeling the Interactions between Aerosols and Liquid Water Clouds with a SelfConsistent Cloud Scheme in a General Circulation Model, J. Atmos. Sci., 64, 1189-1209, doi:10.1175/JAS3874.1, 2007.

Ming, Y., Ramaswamy, V., and Persad, G.: Two opposing effects of absorbing aerosols on global-mean precipitation, Geophys. Res. Lett., 37, L13701, doi:10.1029/2010GL042895, 2010.

Ming, Y., Ramaswamy, V., and Chen, G.: A Model Investigation of Aerosol-Induced Changes in Boreal Winter Extratropical Circulation, J. Climate, 24, 6077-6091, doi:10.1175/2011JCLI4111.1, 2011.

Myhre, G., Shindell, D., Bréon, F.-M., Collins, W., Fuglestvedt, J., Huang, J., Koch, D., Lamarque, J.-F., Lee, D., Mendoza,
B., Nakajima, T., Robock, A., Stephens, G., Takemura, T., and Zhang, H.: Anthropogenic and Natural Radiative Forcing, in: Climate Change 2013: The Physical Science Basis. Contribution of Working Group I to the Fifth Assessment Report of the Intergovernmental Panel on Climate Change, edited by: Stocker, T. F., Qin, D., Plattner, G.-K., Tignor, M., Allen, S. K., Boschung, J., Nauels, A., Xia, Y., Bex, V., and Midgley, P. M., Cambridge University Press, Cambridge, UK and New York, NY, USA, 659740, doi:10.1017/CBO9781107415324.018, 2013.

Naik, V., Horowitz, L. W., Fiore, A. M., Ginoux, P., Mao, J., Aghedo, A. M., and Levy, H.: Impact of preindustrial to presentday changes in short-lived pollutant emissions on atmospheric composition and climate forcing, J. Geophys. Res.-Atmos., 118, 8086-8110, doi:10.1002/jgrd.50608, 2013.

Peters, G. P., Andrew, R. M., Boden, T., Canadell, J. G., Ciais, P., Le Quéré, C., Marland, G., Raupach, M. R., and Wilson, C.: The challenge to keep global warming below $2{ }^{\circ} \mathrm{C}$, Nature Clim. Change, 3, 4-6, doi:10.1038/nclimate1783, 2012.

Putnam, W. M. and Lin, S.-J.: Finite-volume transport on various cubed-sphere grids, J. Comput. Phys., 227, 55-78, 2007.

Pye, H. O. T., Liao, H., Wu, S., Mickley, L. J., Jacob, D. J., Henze, D. K., and Seinfeld, J. H.: Effect of changes in climate and emissions on future sulfate-nitrate-ammonium aerosol levels in the United States, J. Geophys. Res., 114, D01205, doi:10.1029/2008JD010701, 2009.

Quaas, J., Ming, Y., Menon, S., Takemura, T., Wang, M., Penner, J. E., Gettelman, A., Lohmann, U., Bellouin, N., Boucher, O., Sayer, A. M., Thomas, G. E., McComiskey, A., Feingold, G., Hoose, C., Kristjánsson, J. E., Liu, X., Balkanski, Y., Donner, L. J., Ginoux, P. A., Stier, P., Grandey, B., Feichter, J., Sednev, I., Bauer, S. E., Koch, D., Grainger, R. G., Kirkevåg, A., Iversen, T., Seland, Ø., Easter, R., Ghan, S. J., Rasch, P. J., Morrison, H., Lamarque, J.-F., Iacono, M. J., Kinne, S., and Schulz, M.: Aerosol indirect effects - general circulation model intercomparison and evaluation with satellite data, Atmos. Chem. Phys., 9, 8697-8717, doi:10.5194/acp-9-8697-2009, 2009.

Radke, L. F., Coakley, J. A., and King, M. D.: Direct and remote sensing observations of the effects of ships on clouds, Science, 246, 1146-1149, doi:10.1126/science.246.4934.1146, 1989.

Ramanathan, V., Crutzen, P. J., Kiehl, J. T., and Rosenfeld, D.: Aerosols, climate, and the hydrological cycle, Science, 294, 2119-2124, doi:10.1126/science.1064034, 2001.

Reddington, C. L., McMeeking, G., Mann, G. W., Coe, H., Frontoso, M. G., Liu, D., Flynn, M., Spracklen, D. V., and Carslaw, K. S.: The mass and number size distributions of black carbon aerosol over Europe, Atmos. Chem. Phys., 13, 4917-4939, doi:10.5194/acp-13-4917-2013, 2013.

Riahi, K., Grübler, A., and Nakicenovic, N.: Scenarios of longterm socio-economic and environmental development under climate stabilization, Technol. Forecast. Soc., 74, 887-935, doi:10.1016/j.techfore.2006.05.026, 2007.

Riahi, K., Rao, S., Krey, V., Cho, C., Chirkov, V., Fischer, G., Kindermann, G., Nakicenovic, N., and Rafaj, P.: RCP 8.5 - A scenario of comparatively high greenhouse gas emissions, Climatic Change, 109, 33-57, doi:10.1007/s10584-011-0149-y, 2011.

Rogelj, J., Rao, S., Mccollum, D. L., Pachauri, S., Klimont, Z., Krey, V., and Riahi, K.: Air-pollution emission ranges consistent with the representative concentration pathways, Nature Climate Change, 4, 446-450, doi:10.1038/NCLIMATE2178, 2014. 
Rosenfeld, D.: Suppression of Rain and Snow by Urban and Industrial Air Pollution, Science, 287, 1793-1796, doi:10.1126/science.287.5459.1793, 2000.

Rosenfeld, D., Lohmann, U., Raga, G. B., O’Dowd, C. D., Kulmala, M., Fuzzi, S., Reissell, A., and Andreae, M. O.: Flood or drought: how do aerosols affect precipitation?, Science, 321, 1309-13, doi:10.1126/science.1160606, 2008.

Rotstayn, L. D.: On the "tuning" of autoconversion parameterizations in climate models, J. Geophys. Res., 105, 15495, doi:10.1029/2000JD900129, 2000.

Rotstayn, L. D., Collier, M. A., Chrastansky, A., Jeffrey, S. J., and Luo, J.-J.: Projected effects of declining aerosols in RCP4.5: unmasking global warming?, Atmos. Chem. Phys., 13, 1088310905, doi:10.5194/acp-13-10883-2013, 2013.

Sanford, T., Frumhoff, P. C., Luers, A., and Gulledge, J.: The climate policy narrative for a dangerously warming world, Nature Clim. Change, 4, 164-166, doi:10.1038/nclimate2148, 2014.

Shindell, D. T., Schulz, M., Ming, Y., Takemura, T., Faluvegi, G., and Ramaswamy, V.: Spatial scales of climate response to inhomogeneous radiative forcing, J. Geophys. Res., 115, D19110, doi:10.1029/2010JD014108, 2010.

Shindell, D. T., Kuylenstierna, J. C. I., Vignati, E., van Dingenen, R., Amann, M., Klimont, Z., Anenberg, S. C., Muller, N., Janssens-Maenhout, G., Raes, F., Schwartz, J., Faluvegi, G., Pozzoli, L., Kupiainen, K., Höglund-Isaksson, L., Emberson, L., Streets, D., Ramanathan, V., Hicks, K., Oanh, N. T. K., Milly, G., Williams, M., Demkine, V., and Fowler, D.: Simultaneously mitigating near-term climate change and improving human health and food security, Science, 335, 183-189, doi:10.1126/science.1210026, 2012a.

Shindell, D. T., Voulgarakis, A., Faluvegi, G., and Milly, G.: Precipitation response to regional radiative forcing, Atmos. Chem. Phys., 12, 6969-6982, doi:10.5194/acp-12-6969-2012, 2012b.

Shindell, D. T., Lamarque, J.-F., Schulz, M., Flanner, M., Jiao, C., Chin, M., Young, P. J., Lee, Y. H., Rotstayn, L., Mahowald, N., Milly, G., Faluvegi, G., Balkanski, Y., Collins, W. J., Conley, A. J., Dalsoren, S., Easter, R., Ghan, S., Horowitz, L., Liu, X., Myhre, G., Nagashima, T., Naik, V., Rumbold, S. T., Skeie, R., Sudo, K., Szopa, S., Takemura, T., Voulgarakis, A., Yoon, J.-H., and Lo, F.: Radiative forcing in the ACCMIP historical and future climate simulations, Atmos. Chem. Phys., 13, 2939-2974, doi:10.5194/acp-13-2939-2013, 2013.

Smith, S. J. and Bond, T. C.: Two hundred fifty years of aerosols and climate: the end of the age of aerosols, Atmos. Chem. Phys., 14, 537-549, doi:10.5194/acp-14-537-2014, 2014.

Stevens, B. and Feingold, G.: Untangling aerosol effects on clouds and precipitation in a buffered system, Nature, 461, 607-613, doi:10.1038/nature08281, 2009.

Tai, A. P. K., Mickley, L. J., and Jacob, D. J.: Correlations between fine particulate matter $\left(\mathrm{PM}_{2.5}\right)$ and meteorological variables in the United States: Implications for the sensitivity of $\mathrm{PM}_{2.5}$ to climate change, Atmos. Environ., 44, 3976-3984, doi:10.1016/j.atmosenv.2010.06.060, 2010.

Tai, A. P. K., Mickley, L. J., Jacob, D. J., Leibensperger, E. M., Zhang, L., Fisher, J. A., and Pye, H. O. T.: Meteorological modes of variability for fine particulate matter $\left(\mathrm{PM}_{2.5}\right)$ air quality in the United States: implications for $\mathrm{PM}_{2.5}$ sensitivity to climate change, Atmos. Chem. Phys., 12, 3131-3145, doi:10.5194/acp12-3131-2012, 2012.
Takemura, T.: Distributions and climate effects of atmospheric aerosols from the preindustrial era to 2100 along Representative Concentration Pathways (RCPs) simulated using the global aerosol model SPRINTARS, Atmos. Chem. Phys., 12, 1155511572, doi:10.5194/acp-12-11555-2012, 2012.

Thomson, A. M., Calvin, K. V., Smith, S. J., Kyle, G. P., Volke, A., Patel, P., Delgado-Arias, S., Bond-Lamberty, B., Wise, M. A., Clarke, L. E., and Edmonds, J. A.: RCP4.5: a pathway for stabilization of radiative forcing by 2100 , Climatic Change, 109 , 77-94, doi:10.1007/s10584-011-0151-4, 2011.

Tie, X.: Assessment of the global impact of aerosols on tropospheric oxidants, J. Geophys. Res., 110, D03204, doi:10.1029/2004JD005359, 2005.

Twomey, S.: Pollution and the Planetary Albedo, Atmos. Env., 8, 1251-1256, doi:10.1016/0004-6981(74)90004-3, 1974.

Unger, N., Shindell, D. T., and Wang, J. S.: Climate forcing by the on-road transportation and power generation sectors, Atmos. Environ., 43, 3077-3085, doi:10.1016/j.atmosenv.2009.03.021, 2009.

Van Ruijven, B., Urban, F., Benders, R. M. J., Moll, H. C., van der Sluijs, J. P., de Vries, B., and van Vuuren, D. P.: Modeling Energy and Development: An Evaluation of Models and Concepts, World Dev., 36, 2801-2821, doi:10.1016/j.worlddev.2008.01.011, 2008.

Van Vuuren, D. P. and Carter, T. R.: Climate and socio-economic scenarios for climate change research and assessment: reconciling the new with the old, Climatic Change, 122, 415-429, doi:10.1007/s10584-013-0974-2, 2013.

Van Vuuren, D. P., Edmonds, J., Kainuma, M., Riahi, K., Thomson, A., Hibbard, K., Hurtt, G. C., Kram, T., Krey, V., Lamarque, J.F., Masui, T., Meinshausen, M., Nakicenovic, N., Smith, S. J., and Rose, S. K.: The representative concentration pathways: an overview, Climatic Change, 109, 5-31, doi:10.1007/s10584-0110148-z, 2011a.

Van Vuuren, D. P., Stehfest, E., Elzen, M. G. J., Kram, T., Vliet, J., Deetman, S., Isaac, M., Klein Goldewijk, K., Hof, A., Mendoza Beltran, A., Oostenrijk, R., and Ruijven, B.: RCP2.6: exploring the possibility to keep global mean temperature increase below $2{ }^{\circ} \mathrm{C}$, Climatic Change, 109, 95-116, doi:10.1007/s10584-0110152-3, 2011b.

Van Vuuren, D. P., Riahi, K., Moss, R., Edmonds, J., Thomson, A., Nakicenovic, N., Kram, T., Berkhout, F., Swart, R., Janetos, A., Rose, S. K., and Arnell, N.: A proposal for a new scenario framework to support research and assessment in different climate research communities, Global Environ. Chang., 22, 21-35, doi:10.1016/j.gloenvcha.2011.08.002, 2012.

World Health Organization: Special Report on Mortality from ambient and household air pollution in 2012 - summary of results. Programme in public health, social and environmental determinants of health (PHE), available at: www.who.int/phe (last access: 28 October 2015), 2014. 